ISSN: 0514-7336

DOI: http://dx.doi.org/10.14201/zephyrus201473171193

\title{
POBLAMIENTO IBÉRICO Y ROMANO EN SIERRA MORENA ORIENTAL: EL CASTILLO DE BURGALIMAR (BAÑOS DE LA ENCINA, JAÉN)
}

\section{Iberian and Roman settlement in Eastern Sierra Morena: Burgalimar castle (Baños de la Encina, Jaén)}

Luis Arboledas Martínez*, Julio Miguel Román Punzón**, Juan Jesús Padilla Fernández*** y Sebastián MoYa GARCÍA ${ }^{* * * *}$

* Instituto de Historia. Centro de Ciencias Humanas y Sociales. CSIC. C/ Albasanz, 26-28. 28037 Madrid. Correo-e:luis.arboledas@cchs.csic.es

** Dpto. de Prehistoria y Arqueología. Facultad de Filosofía y Letras. Campus de la Cartuja, s/n. 18071 Granada. Correo-e: romanpunzon@gmail.com

*** Dpto. de Prehistoria. Facultad de Geografía e Historia. Cl Profesor Aranguren, s/n. UCM. 28040 Madrid. Correo-e: juanjpad@ucm.es

****Arqueólogo profesional. Cl San Francisco Javier, 1, 2. C. 23006 Jaén. Correo-e: platero@amsystem.es

Recepción: 24/07/2013; Revisión: 6/02/2014; Aceptación: 12/03/2014

BIBLID [0514-7336 (2014) LXXIII, enero-junio; 171-193]

RESUMEN: En este artículo se presenta un primer análisis de los restos arqueológicos de las fases ibérica -Ibérico pleno y final, ss. V-I a. C.- y romana -altoimperial- exhumados durante la intervención arqueológica llevada a cabo entre 2007 y 2008 en el interior del castillo medieval de Burgalimar (Bańos de la Encina, Jaén). Hasta el momento, estos son los únicos vestigios de poblamiento del Ibérico pleno documentados en el interior de la cuenca minera del Rumblar -Sierra Morena oriental-, que sí muestra una fuerte ocupación en los periodos precedentes -Edad del Bronce- y posteriores -época romana-. Por ello, su estudio es fundamental tanto para proponer las primeras hipótesis acerca de la caracterización de este yacimiento como para completar desde una perspectiva diacrónica cómo evolucionó el poblamiento de esta región vinculada a los grandes oppida del valle del Guadalquivir -Castulo, Isturgi o Cantigi-.

Palabras clave: Ibérico pleno. Época altoimperial. Cuenca del Rumblar. Asentamiento ibérico. Aedicula.

ABSTRACT: The main objective of this paper is to present a first analysis of the archaeological remains of the Iberian -Middle and Late Iberian- and Roman -High imperial period- phases documented during the archaeological excavation that took place between 2007 and 2008 in the medieval castle of Burgalimar (Baños de la Encina, Jaén). These are the only remains documented within the mining area of the Rumblar -Eastern Sierra Morena- that belong to the Pre-roman period, where, on the other hand, a strong occupancy has been documented earlier, during the Bronze Age, and later, during the Roman period. Therefore, this study is important for proposing the first hypothesis about the function and type of this settlement, as well as for understanding, from a diachronic point of view, the urban development of this region, which is linked to the largest oppida in the Upper Guadalquivir Valley -Castulo, Isturgi or Cantigi-.

Key words: Middle Iberian Period. Early Roman Empire. Rumblar Valley. Iberian settlement. Aedicula. 


\section{Introducción: el asentamiento y el medio físico $^{1}$}

El yacimiento del castillo de Burgalimar se localiza en el extremo so de la localidad de Baños de la Encina², sobre la cima del Cerro del Cueto -UTM: $\mathrm{X}=432049$ e $\mathrm{Y}=4224968,429$ m.s.n.m.y enclavado en las primeras estribaciones montañosas del SE de Sierra Morena oriental. Su posición, justo en el contacto con la llanura de la Depresión de Linares-Bailén, le convierte en un punto estratégico en la divisoria de la sierra y el valle (Fig. 1). Se trata de un cerro de planta ovalada y cima amesetada cuyas vertientes presentan una pendiente acusada, excepto la ladera $\mathrm{N}$, más suave y de fácil acceso, que conecta con el centro histórico de esta población (Fig. 2).

Como consecuencia de su ubicación, el cerro se encuentra rodeado por dos tipos de terrenos bien diferenciados geológica, edafológica y morfológicamente. Por un lado, al o y el $\mathrm{N}$ se abren los suelos paleozoicos del interior de la sierra, que son poco aptos para la agricultura, pero que, por el contrario, sí lo son para la ganadería y la actividad cinegética. Del mismo modo, en estos suelos pobres encajan los filones con mineralización de cobre, plomo y plata (galenas argentíferas) que

\footnotetext{
${ }^{1}$ En estas líneas queremos expresar nuestro más sincero agradecimiento a J. A. Pachón Romero, por darnos las premisas adecuadas y acertadas durante el estudio de la cerámica ibérica; a A. Beltrán y M. Pastor, por llevar a cabo la transcripción e interpretación de la inscripción recuperada en el castillo; a B. Soler Huertas, por orientarnos en la identificación inicial de los capiteles exhumados. Por último, pero no por ello menos importante, agradecemos a J. A. Domingo Magańa el primer análisis y descripción de los capiteles.

${ }^{2}$ Este artículo se enmarca en los siguientes proyectos de investigación: "La minería en el Alto Guadalquivir. Formas de construcción histórica en la antigüedad a partir de la producción, consumo y distribución de los metales" (HAR2011-30131-C02-01, Proyecto I + D + i del MCI), dirigido por F. Contreras Cortés; "La minería romana en Sierra Morena oriental: formas de estructuración de un territorio a partir de la producción, consumo y distribución de los metales" (PGI de la C. de Cultura de la J. de Andalucía), dirigido por L. Arboledas Martínez; "Paisajes de dominación y resistencia. Procesos de apropiación y control social y territorial en el Noroeste hispano. Proyecto PADORE" (HAR2012-33774, Proyecto I + D + i del MCI), dirigido por A. Orejas Saco del Valle.
}

han sido explotados desde la Prehistoria reciente hasta la actualidad, favoreciendo el poblamiento en la región (Contreras y Dueñas, 2010). El yacimiento minero más cercano a este asentamiento se encuentra a $1 \mathrm{~km}$ hacia el so, en el cerro de enfrente. Se trata de un filón con mineralización de cobre y plomo-plata de más de $1 \mathrm{~km}$, encajado en las pizarras del Culm.

Por otro lado, al E y al S se encuentran los suaves relieves miocénicos y cuaternarios de la campiña -margas, arcillas, conglomerados-, muy aptos para la actividad agrícola, que se extienden por toda la depresión de Linares-Bailén-La Carolina hasta el batolito granítico de Linares y el río Guadalquivir. Desde la cima del Cerro del Cueto se domina con facilidad un amplio territorio, divisándose claramente toda la llanura de tierra fértil, que en la actualidad es un mar de olivos abierto hacia el NE, E y S. Conecta visualmente con numerosos yacimientos de época iberorromana del entorno, conocidos a partir de los trabajos de prospección llevados a cabo en la depresión de Linares-Bailén, como son Las Marquesas o Cerrillo del $\mathrm{Pico}^{3}$. El control hacia el interior de la sierra, al o y N, como hemos señalado, es limitado debido a la mayor cota de las montańas cercanas, si bien mantiene conexión visual directa con algunas zonas del interior del valle del Rumblar y con la principal explotación minera antigua, Salas de Galiarda.

No cabe duda de que el medio físico del entorno -minas y tierras fértiles- así como su posición estratégica, en conexión directa con las rutas de comunicación entre Andalucía y la Meseta, debieron ser factores fundamentales para que este cerro fuera ocupado sucesivamente, desde la Edad del Cobre hasta la construcción del castillo de Burgalimar y la posterior expansión de la población de Baños de la Encina. Concretamente, en las faldas del Cerro del Cueto convergen diferentes veredas, cañadas y caminos reales -como el Camino Real de Andalucía-, procedentes de la Meseta, que estaban vinculados fundamentalmente

\footnotetext{
${ }^{3}$ Casado Millán, P. J. (2001): El valle medio y bajo del Rumblar durante la época romana. Análisis del poblamiento y captación de recursos. I. El medio y los yacimientos. Trabajo de investigación inédito presentado en 2001 en la Univ. de Granada, pp. 179-181.
} 

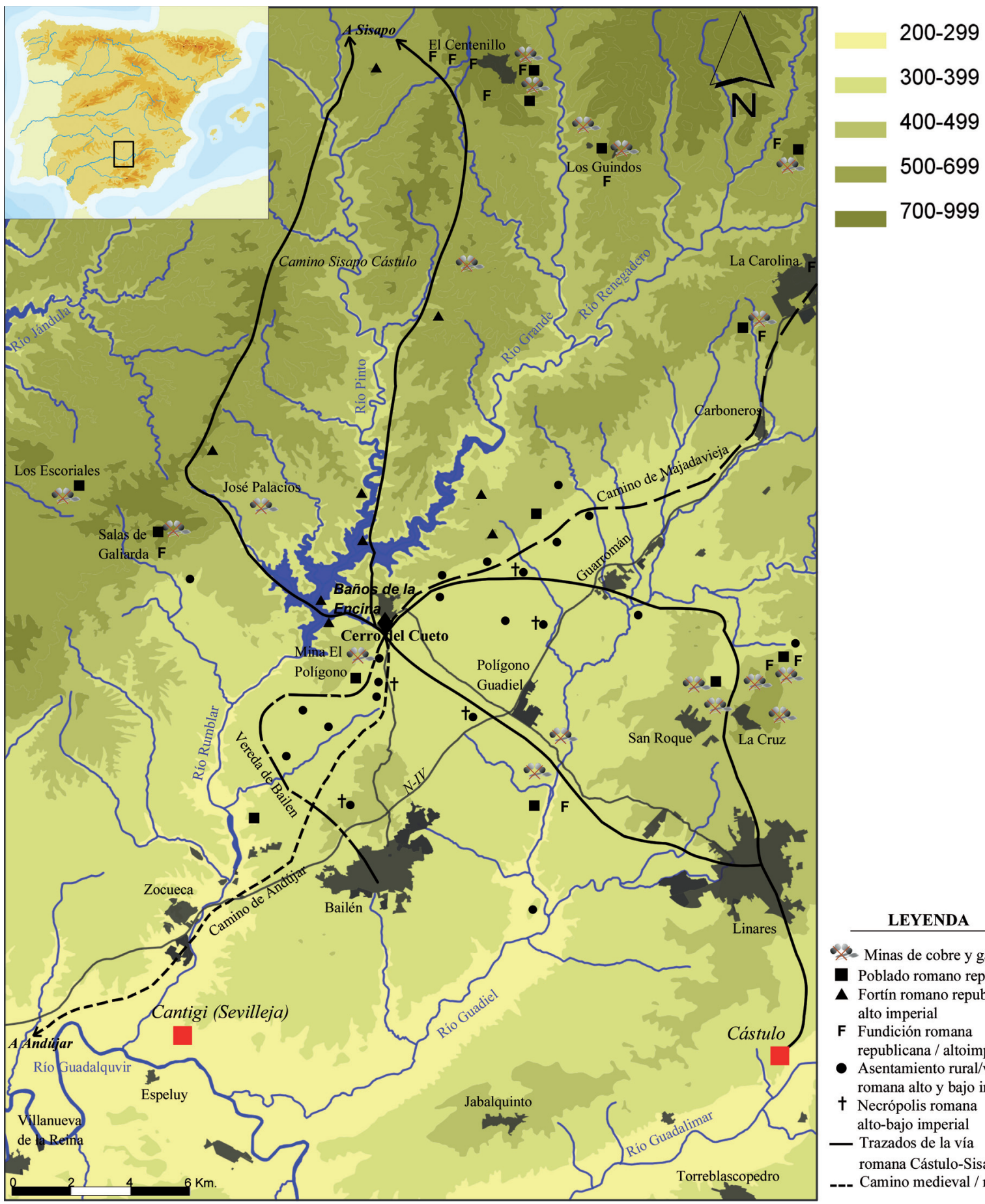

\section{LEYENDA}

Minas de cobre y galena

- Poblado romano republicano

- Fortín romano republicano / alto imperial

F Fundición romana republicana / altoimperial

- Asentamiento rural/villa romana alto y bajo imperial

† Necrópolis romana alto-bajo imperial

— Trazados de la vía romana Cástulo-Sisapo --- Camino medieval / moderno

FIG. 1. Mapa de localización del Cerro del Cueto/castillo de Burgalimar y de dispersión de los principales yacimientos ibéricos y romanos de la cuenca del Rumblar (Jaén). 


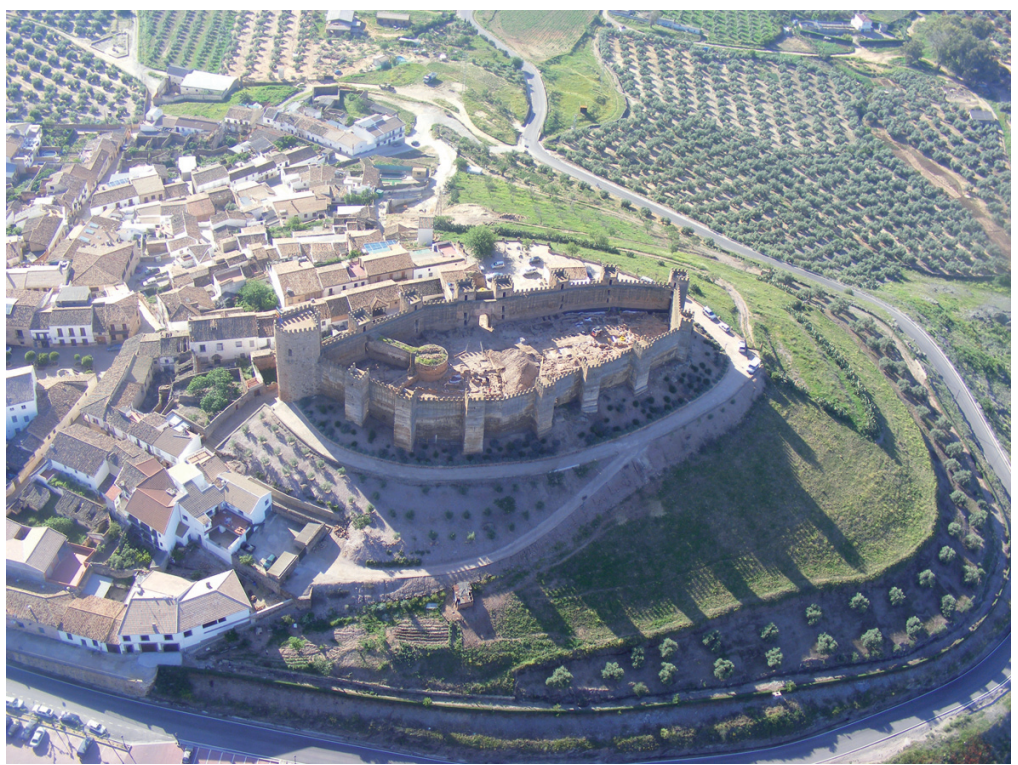

FIG. 2. Panorámica del Cerro del Cueto (Baños de la Encina, Jaén). en varios sondeos estratigráficos y zanjas perimetrales para las obras de drenaje. El objetivo principal era reducir la humedad y la presión que los rellenos ejercían sobre los lienzos, provocando el agrietamiento de los mismos. No obstante, ese objetivo primordial estaba complementado por otros cuatro más: exhumar completamente los enterramientos del interior del castillo, descubrir la importante planta de estructuras medievales de su interior, aclarar las dudas sobre la secuencia estratigráfica-histórica del yacimiento $y$, por último, el estudio y análisis de las nuevas áreas arqueológicas de dicho cerro ${ }^{5}$.

Durante las tareas de excavación se documentó una secuencia completa de ocupación del cerro, en la que se definieron siete fases crono-

a la trashumancia, algunos de los cuales podrían mantener el trazado de vías de épocas precedentes (Corchado y Soriano, 1963; 1969; Cantarero, 2004: 22-35). Recientemente, hemos propuesto la posibilidad de que parte del trazado de la vía romana que unía Sisapo con Castulo transcurriera por el sendero natural del arroyo de Valdeloshuertos, para adentrarse en el valle del Rumblar hasta El Centenillo y cruzar posteriormente hacia tierras manchegas (Arboledas, 2010: 123-132).

\section{La intervención arqueológica del castillo}

La excavación del patio de armas del castillo ${ }^{4}$ se llevó a cabo entre los meses de octubre de 2007 y septiembre de 2008 como continuación de los sondeos arqueológicos realizados en 2002. La intervención consistió en la excavación en extensión del potente relleno que colmataba el interior del castillo hasta los niveles medievales así como

${ }^{4}$ Desarrollada bajo la dirección de S. R. Moya, en el marco del "Proyecto de excavación y drenaje del Patio de Armas del Castillo de Burgalimar, Baños de la Encina (Jaén)", financiado por la C. de Cultura de la J. de Andalucía. culturales: Edad del Cobre, Cultura argárica, Ibérico pleno, fase romana altoimperial, medieval islámica y cristiana -que es la más importante y se vincula a la construcción del castillo y sus posteriores modificaciones-, Época Moderna y la última, desde mediados del s. XIX a 1928 -cuando el patio de armas se convierte en el cementerio local-. Por otro lado, también ha sido posible determinar el momento preciso de construcción del castillo de Burgalimar, a partir de la estratigrafía y de las muestras de C14, en época almohade ${ }^{6}$, concretamente entre el 1120 y 1230.

Los resultados obtenidos en el trascurso de las actuaciones arqueológicas confirman las hipótesis planteadas desde el 'Proyecto Peñalosa' que, tras los primeros trabajos de prospección en la zona, sugerían que este cerro se ocupó desde la Edad del Cobre hasta fechas contemporáneas (Nocete et al., 1987; Lizcano et al., 1990) ${ }^{7}$. Sin embargo, lo más destacado a nuestro juicio ha

\footnotetext{
${ }^{5}$ Moya, S. R.: "Actuación arqueológica puntual en el Castillo de Burgalimar de Baños de la Encina (Jaén), 2007-2009", Anuario Arqueológico de Andalucía. Jaén. 2009. Sevilla, en prensa.

6 Ibidem.

${ }^{7}$ Cf. también Casado: op. cit. n. 3.
} 




FIG. 3. Planimetría general del interior del castillo de Burgalimar (Baños de la Encina, Jaén).

sido el reconocimiento por primera vez de una fase del Ibérico pleno de la que no se tenía constancia, ya que los materiales documentados en superficie únicamente permitían presuponer la existencia de un yacimiento iberorromano, sin mayor precisión. Asimismo, también ha servido tanto para contrastar la información obtenida de la excavación del yacimiento metalúrgico argárico de Peñalosa como para completar el análisis de las comunidades de la Edad del Bronce de esta región minera del Alto Guadalquivir.

La documentación de las fases de ocupación más antiguas propició que los autores de este trabajo colaboráramos en el proceso de investigación de los restos arqueológicos exhumados. En este sentido, nuestra labor se ha centrado en el análisis de las evidencias para las fases ibérica y romana con el objetivo de caracterizar este asentamiento, precisar su cronología y determinar su funcionalidad dentro de la reflexión e interpretación histórica de un territorio más amplio, dependiente seguramente de alguno de los principales centros urbanos del Alto Guadalquivir (Iliturgi, Castulo o Cantigi). Su importancia radica en ser el único yacimiento arqueológico de las cuencas del Rumblar y del Jándula -Sierra Morena oriental- que, hasta el momento, posee en su secuencia estratigráfica una fase atribuible al periodo Ibérico pleno.

\section{La fase ibérica (ss. V-II a. C.)}

Pasamos ahora a considerar el análisis estructural y contextual de los restos arqueológicos de época ibérica documentados en el interior del castillo. Las evidencias de ocupación de esta fase se concentran principalmente en la zona más alta del Cerro del Cueto, en la mitad s del castillo, en los sectores 4, 5, 6, 7, 8, 9, 10 y 11 (Fig. 3).

La asociación de las estructuras exhumadas a los diferentes periodos se ha establecido en función de varios criterios: superposición estratigráfica, tipología, métodos de construcción de los diferentes elementos y estructuración de los espacios, ya que en algunos casos no se conoce la estratigrafía asociada a ellos. Para la fase ibérica ha sido posible vincular varias estructuras gracias a la excavación de ciertos niveles estratigráficos con esta cronología, pero en algún caso parece tratarse de estructuras de la Edad del Bronce reutilizadas en época ibérica ${ }^{8}$.

\subsection{Sector Sur (sondeos 4-5)}

En ambos sondeos, realizados en el extremo $\mathrm{S}$ del castillo, destaca el hallazgo en posición primaria

\footnotetext{
${ }^{8}$ Moya: op. cit. n. 5.
} 


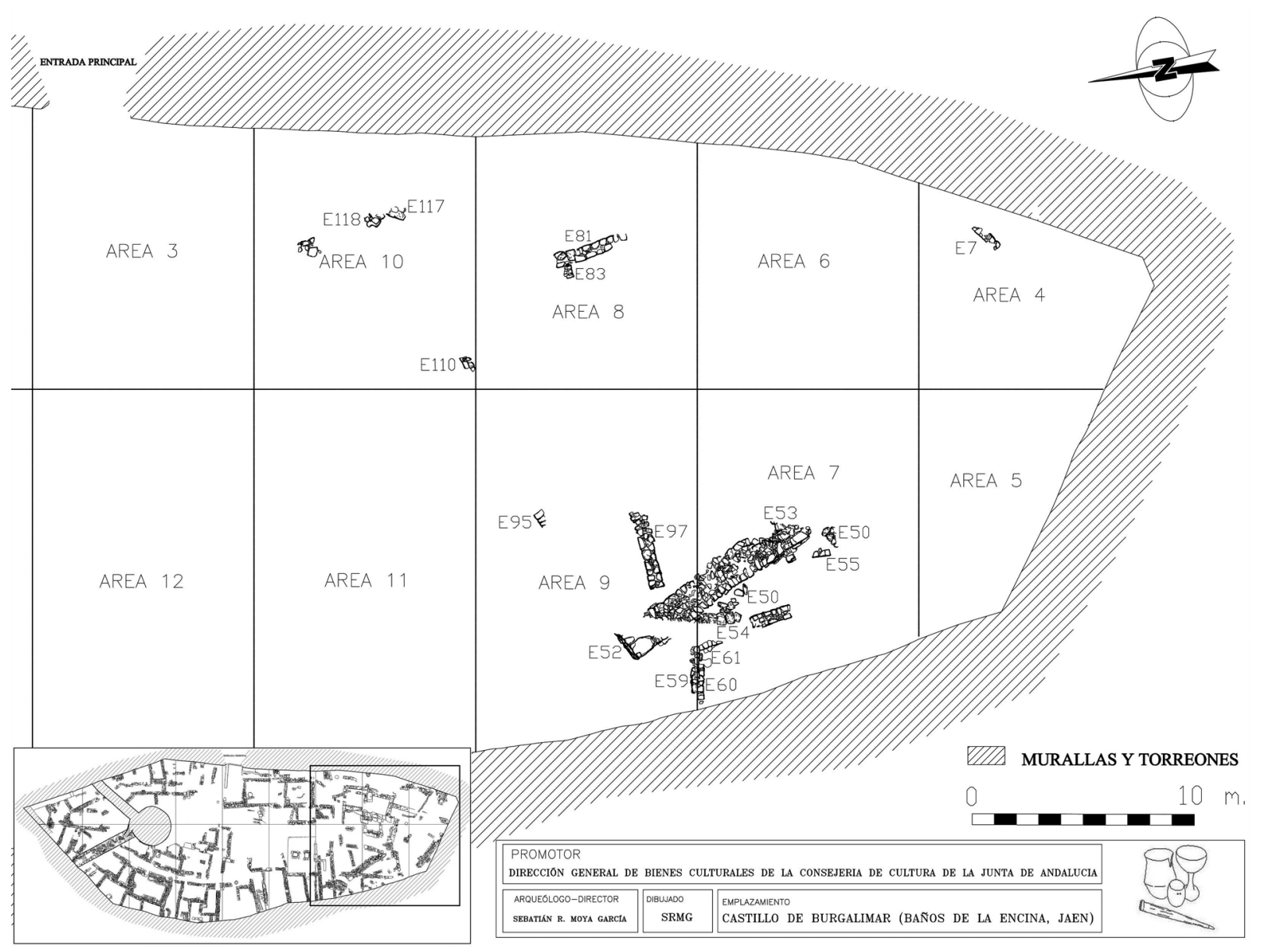

FIG. 4. Planimetría de las estructuras de la fase ibérica del castillo de Burgalimar (Baños de la Encina, Jaén).

de un importante conjunto cerámico del Ibérico pleno asociado a una gran estructura perimetral -E.8- adscrita a la Edad del Bronce pero reutilizada en época ibérica ${ }^{9}$ (Figs. 3 y 4). El grueso de este conjunto material estaba compuesto por cerámica de cocina -fundamentalmente ollas (Figs. 10, n. ${ }^{\text {s }}$ 2 y 6)-, pero también contenía cerámica pintada encuadrable entre los grupos 1 al 6 de la cerámica ibérica de Guadalquivir fechada entre los ss. VI al IV a. C. (Pereira, 1988, 1989). Destaca, sobre todo, un ánfora casi completa de hombro carenado -Tipo 1, Subtipo 1.1 (Mata y Bonet, 1992)-, de inspiración fenicia, y también fechada entre los ss. VI al IV a. C. (Fig. 7, n. ${ }^{\circ} 1$ ). El material se

\section{${ }^{9}$ Ibidem.}

hallaba in situ sobre el suelo de ocupación y debajo del derrumbe de piedras y adobes del alzado de las estructuras que conformarían ese espacio (Fig. 5). Dichos niveles también se documentan con una cierta potencia en las áreas contiguas, sobre todo, en el sector $\mathrm{O}$-cortes 7 y 9 -.

Esos derrumbes ibéricos de adobes del sector $\mathrm{S}$ se asociarían con los alzados de una estancia situada en la parte más alta del cerro. Su límite S-SO estaría marcado probablemente por el muro anteriormente citado -E8-, adscrito a la fase de la Edad del Bronce y reutilizado en este periodo (Fig. 5). Se trata de un muro perimetral del poblado argárico, de más de $1 \mathrm{~m}$ de anchura, del que se conserva un alzado máximo de unos $40 \mathrm{~cm}$. Por tanto, no dudamos que esta estructura 
en época ibérica, con alzados de adobe, también constituyera el límite perimetral del asentamiento ubicado en la cima de este cerro, tal y como sugiere la orientación y arquitectura de la misma.

Entre el material cerámico recuperado en este contexto ibérico se ha identificado un perfil completo de kalathos ibérico pintado, del tipo conocido como sombrero de copa (Fig. 6). El gran interés de esta pieza radica en que, sobre la base de su decoración geométrica y la inusual existencia de doble asa, se le podría atribuir una probable procedencia del área catalana; concretamente parece tratarse de un ejemplar del tipo A2 de Conde i Berdòs (1991: 145) de los alfares ampuritanos. Este

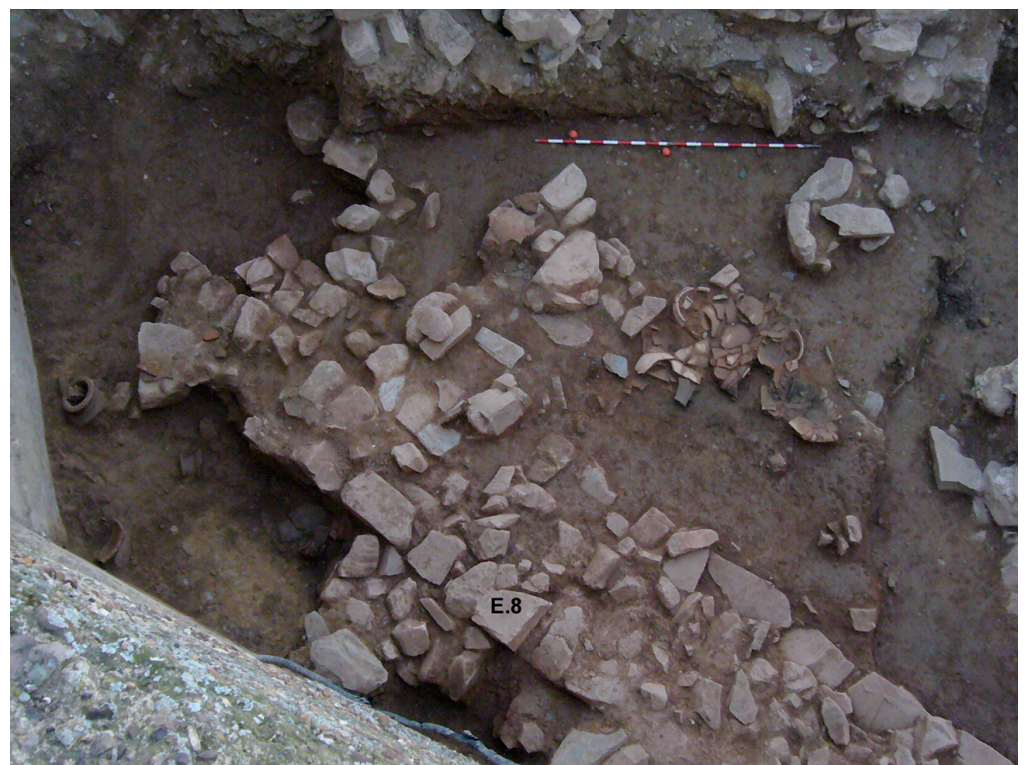

FIG. 5. Niveles de la fase del ibérico pleno del sector 5. hallazgo suscita interrogantes referentes a las relaciones comerciales de la región de Sierra Morena con lugares tan distantes como el referido durante la primera mitad del s. II a. C.

\subsection{Sector Este (sondeos 6, 8 y 10)}

En estos tres sondeos, en la mitad E del patio del castillo, no fue posible definir de manera clara

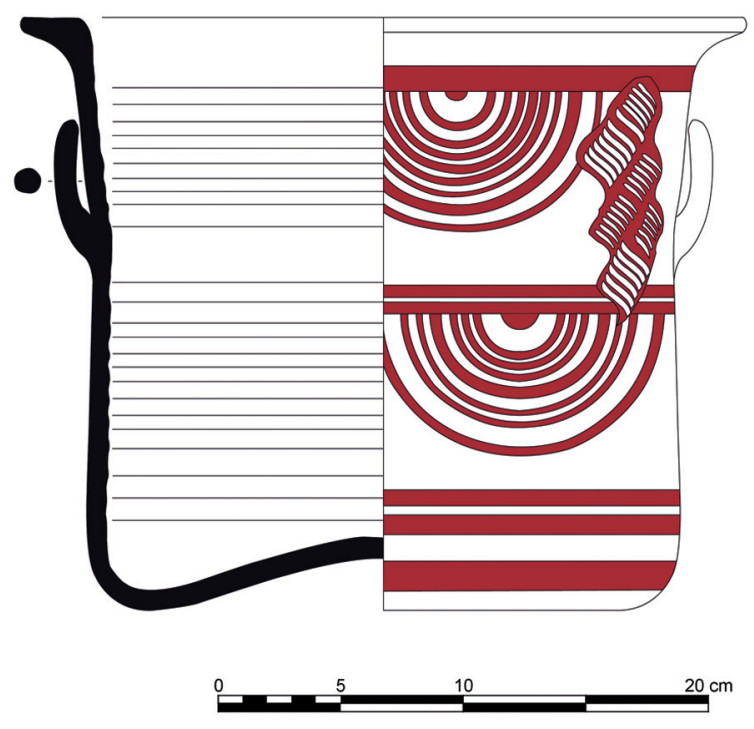

FIG. 6. Kalathos hallado en el castillo de Burgalimar. estratos arqueológicos del periodo ibérico, ya que la cota de afección de la obra se alcanzó antes de agotar la secuencia, y tampoco se documentó una presencia considerable de cultura material. Únicamente, se recuperaron en dos niveles de tierra con manchas de adobe varios fragmentos de ánfora y de pithoi del Ibérico pleno (ss. V-III a. C.) (Fig. 7, n. ${ }^{\circ}$ 3) mezclados con abundante material de la Edad del Bronce. Sin embargo, a nivel estructural, sí se exhumaron cuatro muros de mampostería, dispuestos por parejas formando dos esquinas, que se han adscrito a época ibérica sobre la base de las relaciones estratigráficas, si bien es cierto que con todas las cautelas pertinentes ya que no se ha encontrado material cerámico alguno asociado a los mismos (Figs. 3 y 4).

\subsection{Sector Oeste (sondeos 7 y 9)}

Los sondeos de la mitad o del castillo han proporcionado los mejores contextos arqueológicos, tanto estratigráfica como estructuralmente, de las fases Ibérica y de la Edad del Bronce. En estos sectores se ha podido definir un complejo estructural de época ibérica (C.E.2) que se organizaría en torno a un gran muro, de más de $6 \mathrm{~m}$ de longitud x $1 \mathrm{~m}$ de anchura, al que se asocian toda una serie 

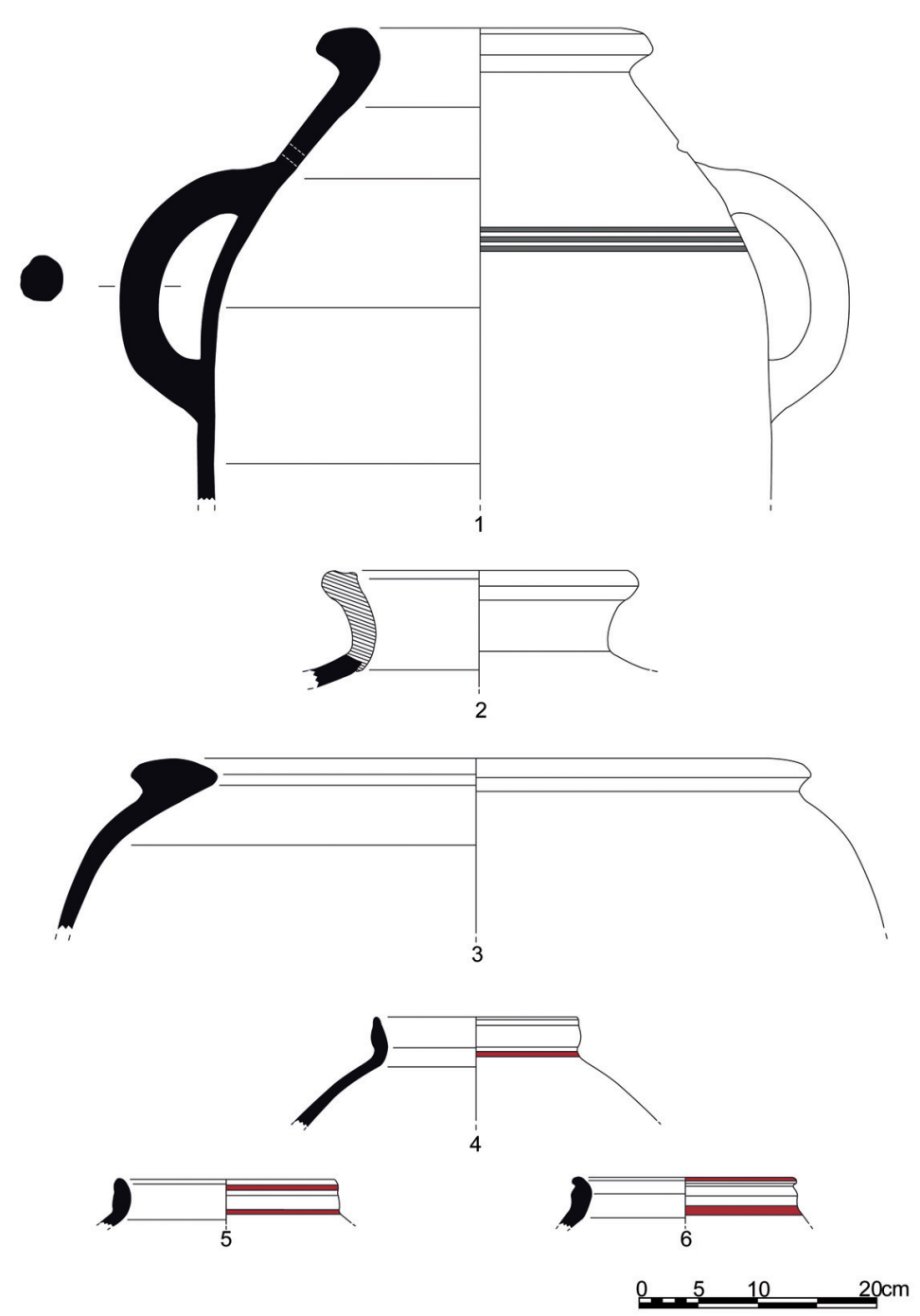

FIG. 7. Cerámica ibérica de almacenamiento recuperada en el castillo de Burgalimar.

de estructuras murarias de menor entidad, a ambos lados, formando diferentes espacios (Figs. 3 y 4). En este sentido, en el lado E se documentó parte del arranque de dos muros de mampostería que formarían, junto al anterior, la esquina $\mathrm{S}$ y $\mathrm{N}$ de un espacio aún por definir. El interior de este espacio debió de estar compartimentado según evidencia el hallazgo de un muro paralelo a los anteriores. Como en el caso anteriormente descrito, tampoco se llegaron a excavar niveles ibéricos asociados a estos muros que permitiesen interpretar adecuadamente este complejo.
$\mathrm{Al}$ o de esta gran estructura se han definido dos complejos o espacios más pequeños bien diferenciados. El primer complejo (C.E. 2a) corresponde a un pasillo o zona de paso, en forma de L, conformado por las estructuras E.52 y 54 y pavimentado de pizarras (E.50), que conectaría diferentes unidades estructurales de este asentamiento (Figs. 3 y 8). Al $\mathrm{N}$ de dicho pasillo y de la E.61, debajo de los estratos medievales, se documentaron dos niveles de derrumbe de adobes de las estructuras ibéricas (E.52 y 61), muy alterados por los procesos postdeposicionales, en los que predominaban los materiales ibéricos sobre los de la Edad del Bronce y romanos. En las partes no afectadas por las fosas de inhumación contemporáneas, se conservaban dos pequeños tramos de un suelo de tierra apisonada de esta época. El tramo localizado junto a la estructura ibérica E.52 contenía un buen número de fragmentos de mineral de plomo - galena-, de escoria de plomo y de paredes de horno o de una solera donde se ha procesado el mineral de plomo, que indicarían el desarrollo de, al menos, una fase del trabajo metalúrgico en esta área.

El segundo espacio -C.E. 2b-, de planta aparentemente rectangular, se encuadra entre las estructuras en forma de L y la muralla del castillo (Fig. 8). La excavación de esta zona permitió evidenciar, bajo los estratos medievales, varios niveles de época ibérica que, en parte, se encontraban alterados por la construcción de los muros medievales y las tumbas contemporáneas. Ello explica la aparición de cerámicas intrusivas, como un fragmento de tégula romana, otro de una posible Forma 1 de TSFT -terra sigillata focense tardía- de los ss. IV-V d.C. o cerámica altomedieval (Fig. 9, n. ${ }^{\circ}$ 7). A pesar de ello, el conjunto mayoritario correspondía a cerámica de época ibérica de diversas producciones -cocina, común, pintada-. 
Entre estos niveles estratigráficos, se identificaron varios de abandono y derrumbe de las estructuras construidas que cubrían un suelo de ocupación con losas de piedra asentadas sobre un barro endurecido del que se conservaba un tramo.

Sobre este suelo, junto a la E52, se encontraban en posición primaria varios objetos cerámicos de época ibérica casi completos, así como algunos fragmentos de escoria de plomo. Se trata fundamentalmente de cerámica de cocina-varios fragmentos de ollas y una tapadera de cerámica a mano (Fig. 5, n. ${ }^{\text {s }} 1,3$ y 4)-, cerámica pintada -dos tinajillas (Fig. 11, n. ${ }^{\text {s }} 2$ y 3 ) - y de almacenaje -dos urnas y un tonel (Fig. 12; Fig. 11, n. ${ }^{\circ} 6$ y Fig. 7 ,

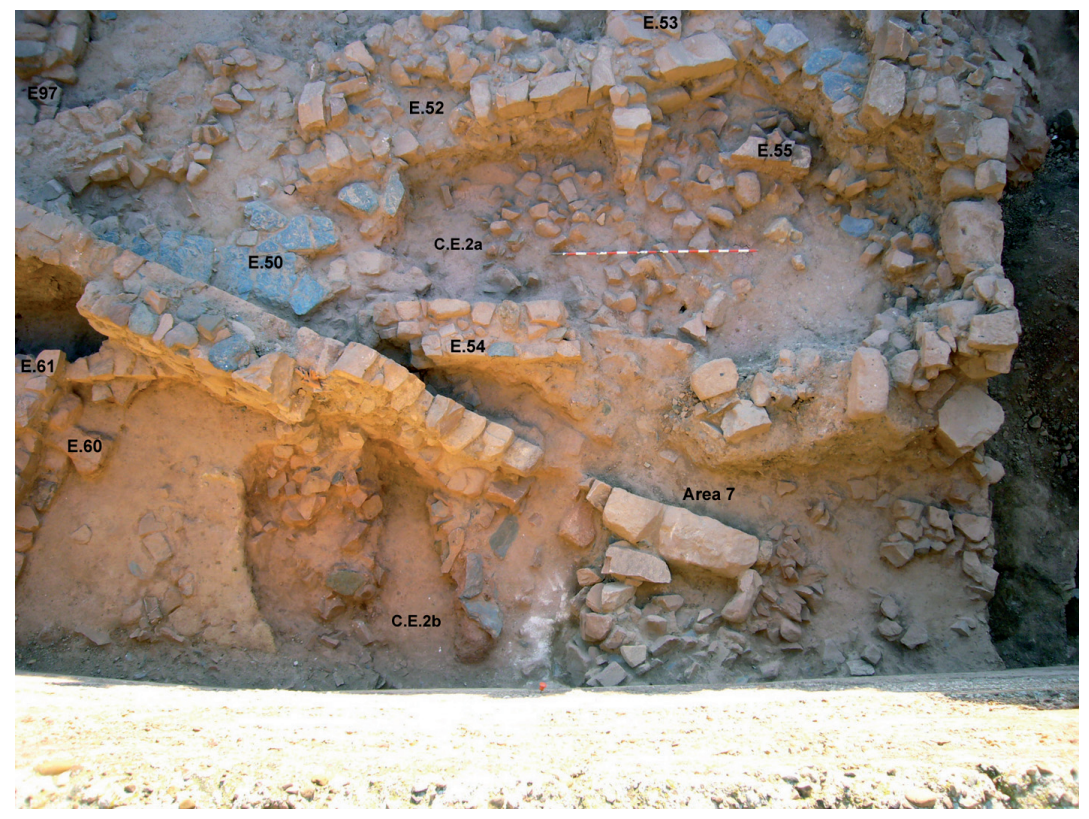

FIG. 8. Complejos estructurales $2 a$ y $2 b$ de la fase ibérica, sectores 7 y 9. n. ${ }^{\circ}$ 2)-, que se vinculan directamente con actividades diarias y de subsistencia. La presencia mayoritaria de este tipo de materiales evidencia que se trata de una estancia de uso cotidiano, probablemente de carácter doméstico, dedicada al almacenamiento, procesado y quizás también al consumo de alimentos (Fig. 11, n. ${ }^{\text {os }} 4-5$ y 7-8) que debió funcionar, según la datación de la cerámica identificada, durante las fases plena y final del periodo ibérico.

\subsection{Sector Norte (sondeos 12-18)}

En el resto del patio del castillo, en la mitad $\mathrm{N}$ (sondeos 12-18) no se han documentado restos arqueológicos relevantes de la fase prerromana, a excepción de algunos fragmentos cerámicos muy rodados hallados en contextos revueltos de época romana y medieval/moderna. Evidentemente se trataría de material de arrastre procedente de la zona alta del cerro, donde se concentra el asentamiento ibérico (Fig. 7, n. ${ }^{\text {s }}$ 4-6).

\section{Fases romana y tardorromana (ss. I-V d. C.)}

De la etapa romana se han registrado escasos restos arqueológicos que, en su mayoría, se localizaban dispersos por los sectores de la mitad $\mathrm{s}$

junto a las únicas estructuras asociadas a esta fase -sondeos 4-9- y por el extremo $\mathrm{N}$ en el alcazarejo -sondeos 13, 16 y 18-. En función de la estratigrafía y tipología se identificaron 5 estructuras muy mal conservadas, debido a la afección de los diversos procesos postdeposicionales. $\mathrm{Al}$ igual que en la fase ibérica, las estructuras se concentran en la parte alta del Cerro del Cueto -sectores 6-9-, formando lo que parece ser un edificio aislado, de planta rectangular y con escalinata de acceso.

De la escalinata de acceso se documentó parte de los dos primeros escalones -uno primero de $2 \mathrm{~m}$ de longitud y $0,50 \mathrm{~m}$ el segundo-, construidos con grandes sillares de arenisca asentados directamente sobre la roca recortada. Seguramente, la escalinata contaría, al menos, con un tercer escalón que alcanzaría el mismo nivel del pavimento original de este espacio, del que quedan las improntas de mortero en superficie. Por la disposición de los muros laterales de este edificio, la escalinata debió tener una anchura de algo más de $5 \mathrm{~m}$ ocupando todo el frente del edificio (Fig. 13).

El límite oriental de este edificio está delimitado por un muro de sillarejo que se adosa a la roca natural recortada (E30) y sobre el que se alzaría otro muro de sillares, del que no se ha conservado nada. El límite o lo marcaría la estructura E51 



FIG. 9. Cerámica romana recuperada en el castillo de Burgalimar.

De la fase romana, y asociado posiblemente a este edificio, se han hallado una inscripción y 3 capiteles corintios, de características toscas y probable procedencia local. $\mathrm{Su}$ hallazgo en diferentes contextos -tanto en los niveles afectados por las fosas de inhumación del cementerio municipal como en otros niveles de derrumbe/relleno- no permite asegurar que esas piezas pertenezcan al yacimiento, pudiendo proceder también de otros lugares cercanos desde donde habrían sido trasladados y reutilizados.

El lugar de hallazgo de uno de los capiteles, a los pies de la escalinata del edificio mencionado, así como su tipología y estilo ${ }^{11}$ parecen concordar cronológicamente con esta construcción. Se trata de un capitel corintio de $0,60 \mathrm{~m}$ de diámetro superior, $0,40 \mathrm{~m}$ de diámetro en la base, $0,70 \mathrm{~m}$ de diámetro mayor superior entre extremos de las hojas de acanto y $0,45 \mathrm{~m}$ de altura aproximada del perfil (Fig. 15). Presenta una talla bastante naturalista, a pesar de haber sido realizado por un taller local con una habilidad técnica no muy desarrollada; las hojas de acanto siguen modelos desarrollados en época

que, con una orientación SO-NE, presenta unas dimensiones de $4,10 \mathrm{~m}$ de longitud por $0,70 \mathrm{~m}$ de anchura. Sin embargo, hasta el momento no se ha definido el muro $\mathrm{N}$ que definiera el edificio por este flanco (Figs. 3 y 14) aunque en el extremo NE se ha documentado la existencia de un posible suelo, trabajado y pulido en la roca cuyos huecos están rellenos de pequeñas piedras y que permite proponer el cierre septentrional de esta construcción. Por último, existen registros estructurales romanos desplazados o en posición secundaria, que se podrían asociar a este edificio, reutilizados en muros y suelos almohades de la trama urbana interior del castillo ${ }^{10}$.

${ }^{10}$ Moya: op. cit. n. 5. augústea en Roma, sobre todo respecto al 'contacto asimétrico de los foliolos'. Los nervios de las hojas de acanto han sido tallados con mucha plasticidad y profundidad, simulando escultóricamente los nervios de las hojas de acanto, mientras que los caulículos tienen un relieve más pronunciado y natural recubierto por membranas vegetales lisas terminadas en uńas. El coronamiento de los caulículos es un bocel liso, si bien a partir de finales de época julio-claudia será muy frecuente la aparición en este lugar de pequeños elementos vegetales de decoración. Por último, las enjutas aparecen desprovistas de todo tipo de decoración. Por

${ }^{11}$ Gutiérrez Behemerid, 1983: 73-104; eadem, 1992; Ramallo, 2004 y Domingo Magańa, 2011. 
todos estos elementos estilísticos este capitel se podría fechar en época julio-claudia, a mediados del s. I d. C.

Los otros dos capiteles presentan unas dimensiones, estilismo y decoración muy diferentes al anterior. El primero, recuperado durante los trabajos de destierre de los niveles del cementerio, en una zona próxima al anterior, es también de un capitel corintio pero con dimensiones más reducidas $-0,27 \mathrm{~m}$ de diámetro en la base y $0,50 \mathrm{~m}$ de diámetro en la parte superior-. A pesar de su estado de conservación, se pueden apreciar algunas características bastantes significativas, como la presencia únicamente de dos pequeños espacios de sombra circulares en las hojas acantizantes, del mismo tipo que aparecen en el coronamiento de los caulículos. Este tipo de hojas es frecuente en las producciones locales hispanas tardorromanas. Por ello, con todas las reservas necesarias al ser un análisis preliminar, pensamos que éste se encuadraría cronológicamente en el s. IV d. C., momento caracterizado por la esquematización de la talla de los elementos decorativos de los capiteles, pero en el que todavía se conservan algunos elementos propios y característicos de las produc-

ciones altoimperiales, que irán desapareciendo a lo largo de los s.

IV-V d. C. Por ejemplo, el caveto inferior del ábaco, que en este ejemplar aparece simplificado en una simple banda, la flor del ábaco, está convertida en una protuberancia que probablemente priva de toda decoración; el labio de los cálatos, exageradamente pronunciado, y los cálices, en los que los elementos vegetales han sido simplificados de tal manera que prácticamente han desaparecido. Por tanto, la presencia de algunas cerámicas junto a este capitel se podría relacionar con una fase de ocupación o, al menos, de frecuentación del cerro, en época tardorromana.
Por último, el tercer capitel también se recuperó en los rellenos revueltos del cementerio del s. XIX, en un área cercana al posible edificio rectangular anteriormente descrito -sector $8-$. Sus dimensiones son mucho más reducidas -unos $0,20 \mathrm{~m}$ de diámetro en la base por $0,40 \mathrm{~m}$ de diámetro en la parte superior-. Según Domingo Magaña, tras un primer análisis ocular, se podría atribuir sin dudas al estilo denominado 'Segundo Triunvirato', presente en Hispania desde finales de la época republicana y a lo largo de toda la época augústea, aunque, en algunos casos y tratándose 



3



4
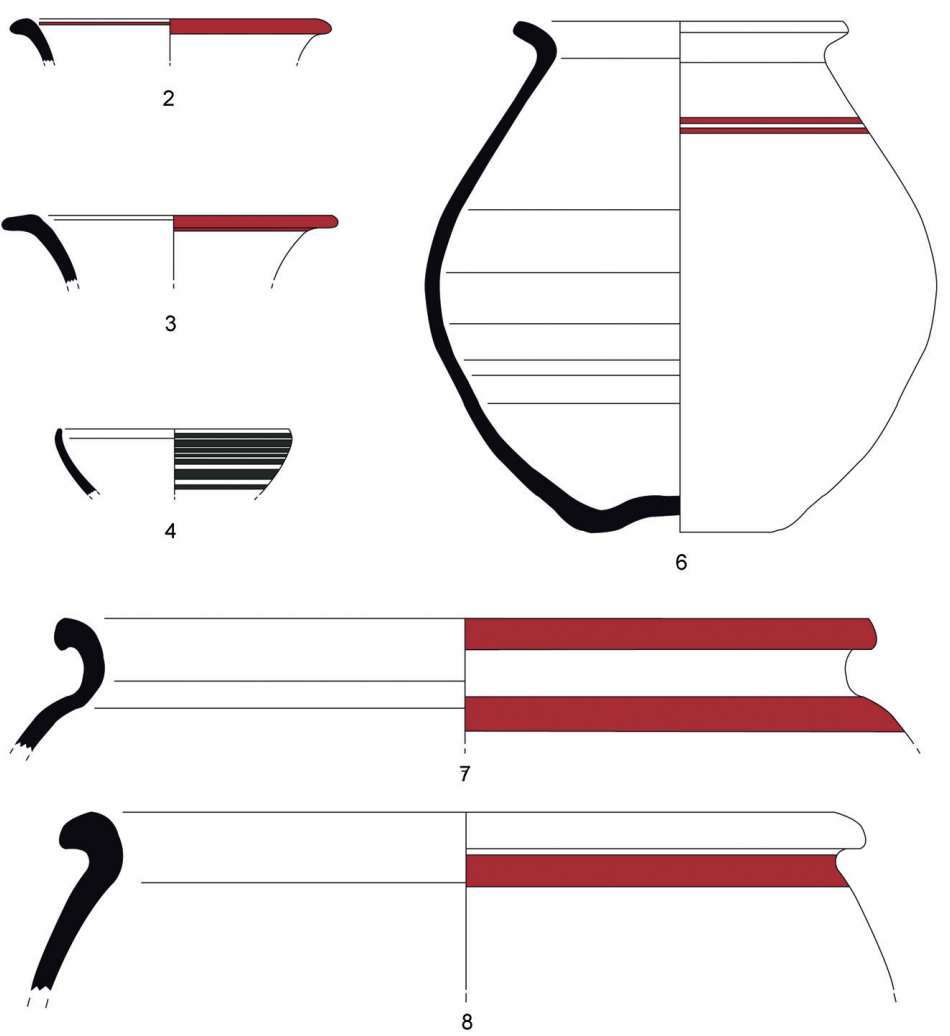

8
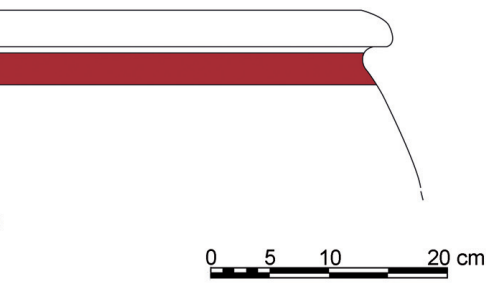

FIG. 11. Cerámica ibérica pintada hallada en el castillo de Burgalimar.

pertenecientes al 'Segundo Triunvirato', como en el presente ejemplar, por lo que su adscripción a esta tipología y a esta cronología resulta bastante clara.

Respecto a la inscripción, resulta complicado comprobar su relación con la fase romana, ya que apareció en los niveles superficiales, revueltos por las sepulturas de época contemporánea. Por ello, y ante los signos evidentes de erosión y huellas de arado, podría tratarse de una pieza reaprovechada en la construcción de las sepulturas contemporáneas. Al igual que en el caso de los capiteles, no podemos garantizar su vinculación con este edificio ni siquiera con el propio yacimiento; es posible también que procediera de una de las numerosas necrópolis asociadas a las grandes villae altoimperiales documentadas en la depresión Linares-Bailén (Pérez Barea et al., 1992) aunque lo más razonable es que, en origen, perteneciera a este asentamiento.

Se trata de un epígrafe fragmentado, realizado en asperón de la zona, que conserva parcialmente las dos primeras líneas (Fig. 16). Sus dimensiones son $30 \mathrm{~cm}$ en la parte más ancha y $21 \mathrm{~cm}$ de altura máxima. Parece que tuvo un remate semicircular, aunque el avanzado estado de erosión, así como su

de producciones realizadas por talleres locales, su uso se prolongó hasta los primeros años de la dinastía julio-claudia. De hecho, en este capitel se encuentran algunas de las características que definen ese estilo, como una decoración vegetal muy esquemática. Así, en las hojas de acanto se generan espacios de sombra circulares seguidos por uno o dos triángulos, y en las enjutas aparece una hoja lisa como decoración, en sustitución de la pequeña roseta que suele aparecer en este lugar en los capiteles de esta cronología realizados con una talla más naturalista. Este espacio del capitel solamente se decora mediante una roseta o un elemento más esquemático en las producciones posible reutilización posterior como material constructivo, podrían haber alterado esta forma.

En cuanto a su lectura, la segunda línea del epígrafe no presenta muchos problemas de transcripción; sin embargo, la primera ha sido transcrita inicialmente como ILICIA aunque hasta el momento no se conoce en la onomástica latina ninguna Ilicia. Por ello, creemos que la opción lógica es interpretar el primer signo como el nexo FE, lo que permitiría transcribir esa grafía como Felicia, un cognomen frecuente y del que se conocen diversos ejemplos en la Bética -en Cádiz (CIL II, 1870) y en Las Cabezuelas (AE 1998)-. Otra opción sería leer [aed]ilicia aunque ésta parece 
poco probable ya que, en ese caso, este término debería ir acompañado de otro como, por ejemplo, potestate. Así pues, pensamos que la forma más coherente de transcribir e interpretar esta inscripción es: Felicia / ita co[- - ] / . . . . .

El epígrafe parece dedicado a una mujer, cuyo cognomen es Felicia y cuya gens se omitió, ya que no parece existir espacio disponible anterior al $\operatorname{cog}$ nomen. Este nombre, Felicia, así como su versión masculina y sus derivados -Felicissima- es frecuente en Hispania y especialmente en la Bética. No es descartable que el nombre estuviera en dativo con un nexo final $A E$, pero la erosión impide afirmarlo de manera rotunda. En la línea 2 se lee claramente ITA, letras que podrían aludir a la origo de esta mujer, ita(licensis)?; esto no debe extrañar dada la cantidad de menciones de la origo presentes en toda la zona de Jaén -así, por ejemplo, Tuccitana, Ilubariensia, Aurgitanus, Cluniensis, Obulconensis, etc. (CILA III)-. A continuación parecen conservarse dos letras correspondientes a otra palabra, ya que su tamaño varía y hay una distancia notable respecto a la palabra anterior, incluso para una posible interpunción. El texto final CO se podría interpretar de diversas formas: como la mención a una colonia o a un collegium ${ }^{12}$, etc., aunque consideramos muy arriesgado sacar conclusiones a partir de tan escasos signos.

Sobre la función de este epígrafe cabe señalar que, dado que se trata de un fragmento, no es posible sugerir si se trata de una inscripción funeraria, votiva u honorífica. Sin embargo, la forma cursiva de algunas letras, especialmente la $L$ y la $A$ de la línea 1 , permite aproximar una datación en época antonina.

Respecto al edificio rectangular, a nivel estratigráfico, ha sido prácticamente imposible definir de manera clara ningún nivel de la fase romana

\footnotetext{
12 No resulta extraña la aparición de epígrafes con menciones a collegia en este tipo de contextos, como demuestra el hallazgo de la inscripción musiva de Loma de Herrerías (Mazarrón), dedicada por los magistri de un collegium, y que pone de manifiesto la importancia de estas corporaciones en el engranaje económico y administrativo de las explotaciones minerometalúrgicas y, además, la entidad edilicia y grado de desarrollo social alcanzado en algunos de estos poblados, en los que comienzan a hacer acto de presencia diversas fórmulas de autorrepresentación (Antolinos et al., 2010: 203).
}

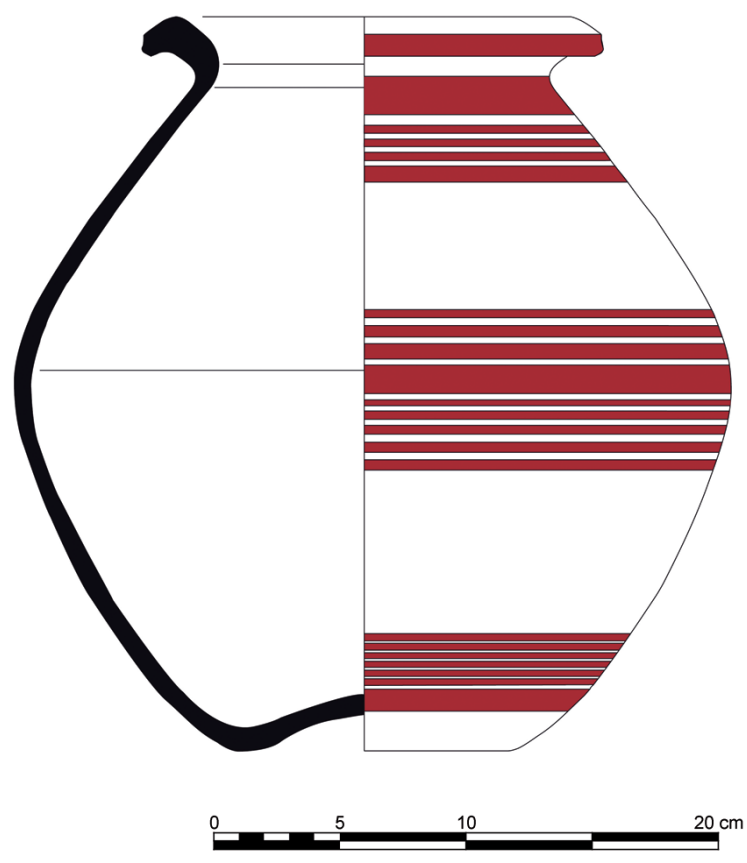

FIG. 12. Urna de cerámica ibérica pintada hallada en el castillo de Burgalimar.

asociado a sus estructuras. A pesar de ello, en los alrededores del mismo, en contextos alterados de época medieval, moderna e incluso ibérica, se han recuperado varios fragmentos de cerámica común, tanto romana como de tradición ibérica, así como tegulae, que se pueden relacionar con la techumbre de esta construcción.

En el conjunto de la plaza de armas del castillo, únicamente se han documentado dos niveles definidos como romanos. Se trata de niveles de abandono/derrumbe con piedras, muy alterados, que incluían gran cantidad de material cerámico muy heterogéneo, con una cronología amplia que abarca desde fechas republicana hasta el s. V d. C. Entre el material documentado, se encuentran morteros de tradición púnica (Fig. 9, n. ${ }^{\circ}$ 3), cerámica común romana de tradición ibérica -como una orza, una tapadera, un lebrillo o pelvis (Fig. 10, n. ${ }^{\circ} 5$ y Fig. 9, n. ${ }^{\text {os }} 1,4$ y 5)-, TSG -Drag. 15/17- o cerámica de cocina africana -tapadera Ostia II, 302 (Fig. 9, n. ${ }^{\circ}$ 2)-, hasta amorfos de TSAC o TSHTM - un borde de la Forma 1-, además de cerámica medieval a torno de pasta grosera. Si bien los materiales tardorromanos, y probablemente los emirales-califales, 


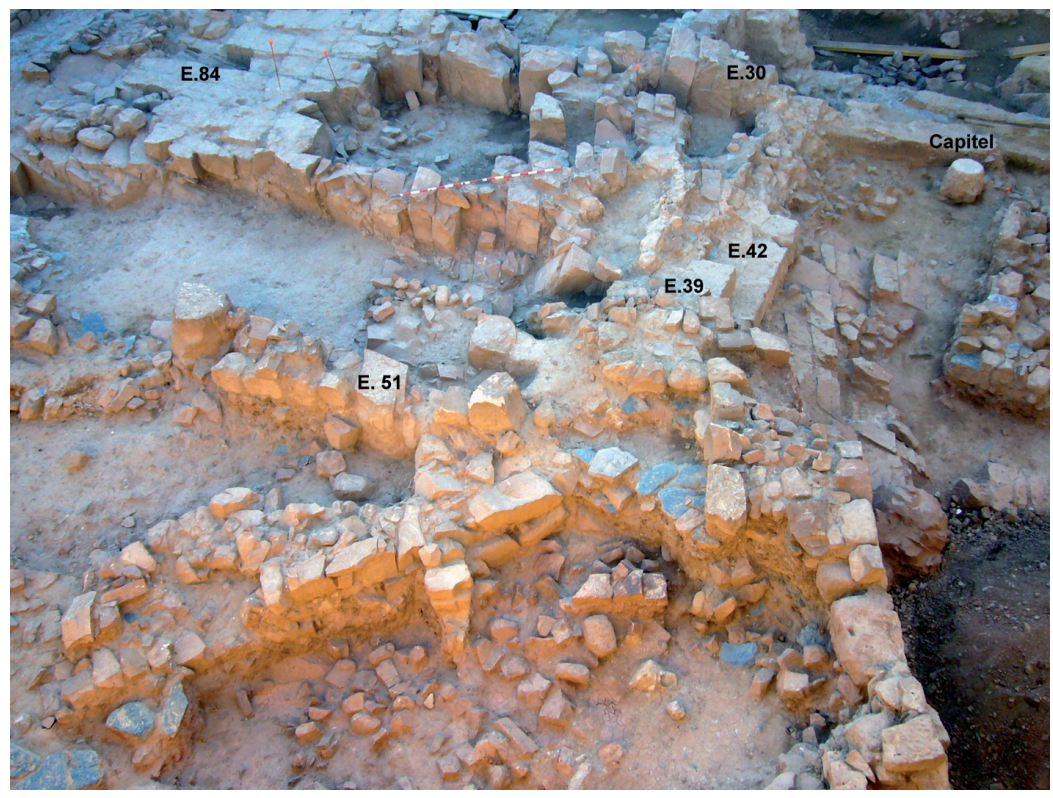

FIG. 13. Restos estructurales del edificio romano.

visualmente toda la vasta llanura de Linares-Bailén y, además, parece encontrarse aislado y sin asociar a otros espacios auxiliares o que lo complementen a su alrededor. Tiene forma rectangular, con unas medidas incompletas de $11,65 \times 5,15 \mathrm{~m}$, aproximadamente, y presenta una escalinata de acceso. Su orientación N/NE-S/SO coincide con la orientación de la mayoría de los templos rurales romanos (Etxeberría, 2008: 270). También podría relacionarse este edificio con un elemento decorativo monumental, como es el capitel corintio recuperado junto a dicha escalinata y datado a mediados del s. I d. C. Igualmente, reaprovechados en estructuras de época islámica almohade de su entorno, aparecieron un gran número de sillares y losas que se

hallados en este yacimiento no permiten establecer una fase de hábitat continuado en el Cerro del Cueto, sí evidencian una frecuentación probablemente puntual del lugar, que tendría un uso indeterminado para este periodo tardío, y en la cual, la ubicación estratégica del mismo debió ser razón fundamental.

En definitiva, la ausencia de información en el casco urbano de Baños de la Encina al respecto de la existencia de restos estructurales de un asentamiento de época romana, que tampoco aparecieron en las diferentes actuaciones arqueológicas realizadas anteriormente en el castillo de Burgalimar (Castillo et al., 1990) ${ }^{13}$, nos inclina a pensar que con esta intervención se han registrado los escasos restos conservados de un edificio de época romana con un evidente carácter monumental. Recapitulemos los datos que conocemos para justificar nuestra hipótesis. Se encuentra ubicado en la zona más alta del cerro y, por tanto, con una posición preeminente sobre el territorio circundante, controlando

${ }^{13}$ Cf. también Moya, S. R. (2002): Actuación arqueológica de urgencia en el Castillo de Baños de la Encina, Jaén. Informe inédito depositado en la Delegación Provincial de Cultura de Jaén. han interpretado como provenientes de este edificio. Asimismo se han recuperado numerosos fragmentos de tégula en los niveles de relleno de los alrededores de esta estructura y que, ante la ausencia de otros edificios de época romana, debieron pertenecer a la cubierta de este singular edificio.

Todo ello nos sugiere que los edificios que más se amoldan a las características señaladas y al registro material y estructural recuperado podrían ser, o bien algún templo o santuario, o bien una construcción conmemorativa, o, incluso, un edificio funerario. A tenor de los escasos restos arqueológicos documentados es difícil decantarse por alguna de las opciones mencionadas y poder determinar cuál sería su funcionalidad y cronología más concreta. Aun así, en este caso proponemos que podría tratarse de un edificio de culto o conmemorativo, no sólo por las características, dimensiones y situación del mismo, sino también por la total inexistencia de cualquier resto funerario de estas fechas. En cuanto a su cronología, la tipología del mismo, los elementos decorativos -capitel-, el material cerámico documentado e, incluso, la posible asociación a este de la inscripción dedicatoria antes descrita, sugieren que habría que adscribirlo a época altoimperial, posiblemente, en torno a mediados del s. I d. C. 


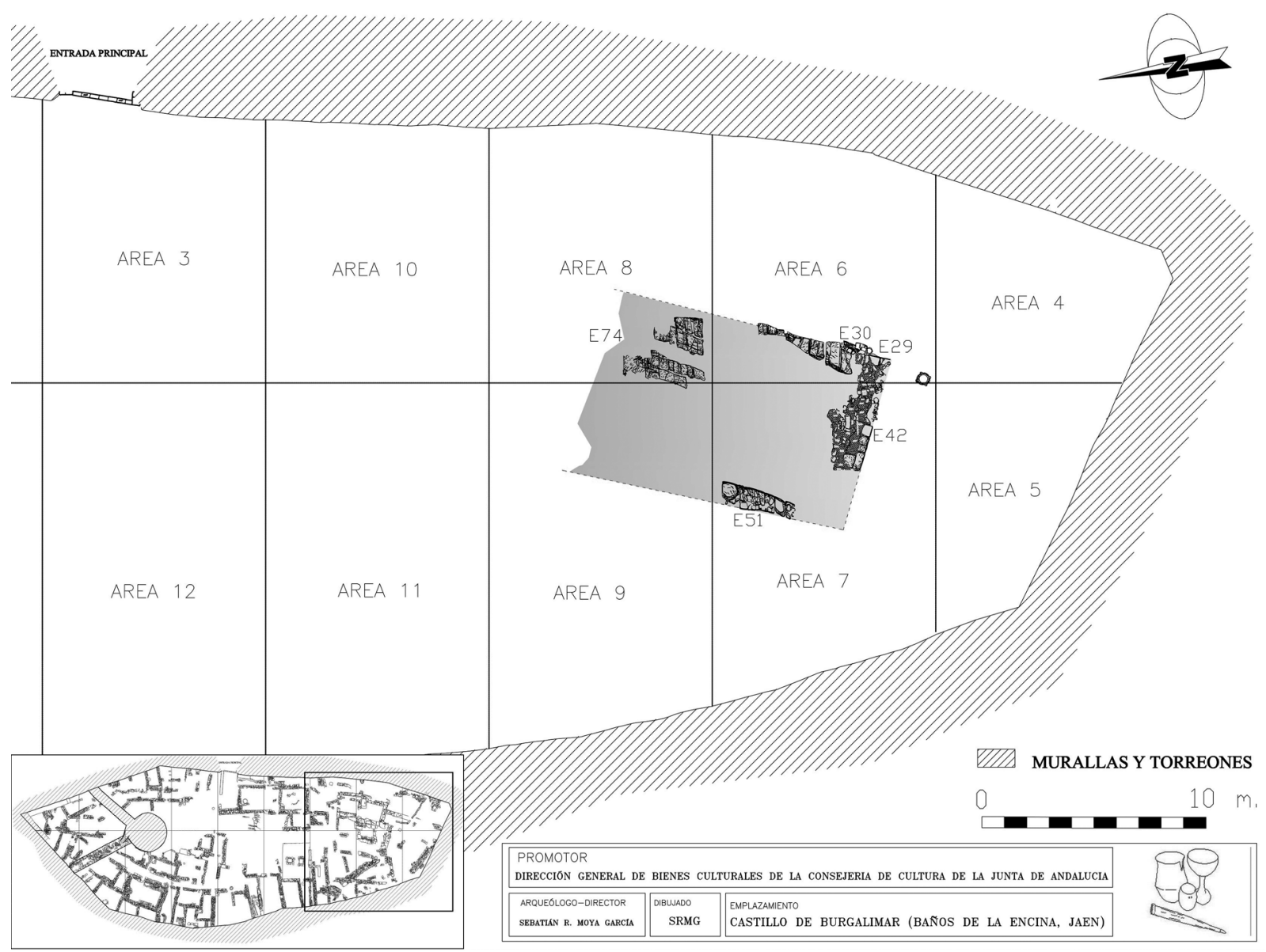

FIG. 14. Planta de los restos del edificio romano.

\section{Conclusiones: hacia la definición de los horizontes ibérico y romano del Cerro del Cueto y de la cuenca del Rumblar}

A pesar de los problemas estratigráficos derivados de los procesos postdeposicionales ya descritos, hoy contamos con suficiente información para plantear algunas hipótesis sobre la definición y caracterización de este yacimiento. Si bien, estas deberán ser ratificadas y completadas en el futuro con la excavación completa y sistemática del castillo (Fig. 3), así como con el estudio arqueológico a escala regional de este territorio jiennense.

\subsection{La fase ibérica}

De esta fase, y atendiendo al nivel en el que se detuvo la excavación de la plaza de armas del castillo, se han podido identificar en los sectores meridional y oriental los zócalos de varias estructuras y restos de diversos pavimentos de tierra bajo los derrumbes de adobe que formarían parte de distintos espacios destinados a diferentes actividades productivas; también se conservaba in situ un completo ajuar cerámico. Los materiales documentados en el sector $\mathrm{S}-$ sondeo $5-\mathrm{y}$ en el C.E. $2 \mathrm{~b}$-sector 7 - se vincularían con actividades cotidianas como el almacenamiento, procesado y consumo de alimentos; sin embargo, los vestigios del C.E. 2a se asocian con la producción de metales de plomo/plata. Por tanto, en este yacimiento se observa una cierta división espacial con usos completamente diferentes.

La distribución y concentración de la mayoría de las evidencias arqueológicas de época ibérica en la parte alta del Cerro del Cueto parece evidenciar 




FIG. 15. Capitel corintio hallado junto a la escalinata del edificio romano.

de estructuras defensivas que avalen esta tesis, aunque ésta no es una condición sine qua non para ello. Otra posibilidad es que estas estructuras, al margen de que muchas de ellas no hayan sido excavadas, fueran destruidas y reutilizadas en las fases de ocupación posteriores.

En todo caso, lo que sí parece evidente es que este yacimiento, por su situación estratégica y privilegiada, debió de estar vinculado tanto a la explotación como al control del territorio circundante y del principal acceso natural al valle del Rumblar y Sierra Morena, el arroyo Valdeloshuertos. A este respecto, debemos recordar dos cuestiones fundamentales que nos pueden ayudar a entender la ubicación de este asentamiento en

claramente que el asentamiento de esta fase se ubicaría estrictamente en la corona del mismo y, más concretamente, en el espolón rocoso más elevado situado en la zona $\mathrm{S}$ del patio del castillo. Hasta el momento, en las laderas del cerro no se han documentado restos arqueológicos de este periodo que evidencien que el asentamiento se extendiera fuera de la cima. Por tanto, dicho yacimiento, en función del volumen y la concentración del material arqueológico en su cumbre, debió tener una escasa entidad y unas dimensiones reducidas - entre 0,3 a 0,5 ha- y, por consiguiente, estaría probablemente ocupado por un reducido grupo poblacional.

En este punto y ante los datos obtenidos resulta obligado preguntarnos qué tipo de asentamiento existió en el Cueto. Por el momento, el registro arqueológico no permite determinar con rotundidad el tipo de hábitat ante el que nos encontramos; pudo ser un emplazamiento defensivo y fortificado, al estilo de los documentados en otras áreas del Alto Guadalquivir (Ruiz et al., 1983; Ruiz y Molinos, 1984) o, simplemente, un pequeño asentamiento rural ubicado en una posición privilegiada. En ambos casos, este dependería de un gran oppidum que, por su cercanía, podría haber sido Castulo. Respecto a la primera de las opciones, no se han documentado hasta el momento grandes evidencias la cima del cerro. La primera, como ya se ha mencionado en apartados anteriores, es la existencia en los alrededores del mismo de tierras muy fértiles aptas para la práctica agrícola y también de numerosas minas de cobre y galena argentífera, como la del Polígono o José Palacios (Arboledas y Contreras, 2010; Arboledas, 2010). Es probable que la mina del Polígono fuera explotada en el periodo ibérico, cuestión que podremos aclarar en el futuro con la comparación de los resultados de los análisis de isótopos de plomo de los restos metalúrgicos hallados en este castillo con los minerales procedentes de esta mina, ya que las evidencias arqueológicas documentadas en superficie son poco concluyentes. Sin embargo, en el resto de las minas reconocidas en el interior de Sierra Morena oriental, no se han constatado aún restos arqueológicos que prueben que estas fueron beneficiadas en momentos ibéricos anteriores al $s$. II a. C., al igual que tampoco se han hallado restos de hábitat de esta época asociados a las mismas $^{14}$. Por tanto, los vestigios del Cerro del Cueto son las primeras y únicas evidencias de hábitat del

${ }^{14}$ Este hecho es una tónica general que se repite y se puede extrapolar a otras regiones mineras del SE peninsular donde apenas se tiene constancia arqueológica de la explotación de las minas en este periodo. 
Ibérico pleno de las que se tiene constancia en esta región minera de Sierra Morena oriental que, por el contrario, sí muestra una fuerte ocupación en los periodos tanto precedentes como posteriores (Nocete et al., 1987; Lizcano et al., 1990; Contreras, 2001; Arboledas, 2010).

Ese vacío documental del interior de Sierra Morena oriental puede tener su origen en una conjunción de factores. El primero estriba en la falta de trabajos de campo y/o investigación, como se ha sugerido en algunos seminarios o congresos; sin embargo, no creemos que este sea el caso de la cuenca del Rumblar y afluentes, ya que dicha zona ha sido objeto de numerosas prospecciones arqueológicas sistemáticas y arqueometalúrgicas, e incluso de excavaciones en el marco del Proyecto Peñalosa



FIG. 16. Fragmento de inscripción hallado en el interior del castillo. (Universidad de Granada), y en ningún caso se han documentado vestigios de esta época, a excepción de los que aquí presentamos. Un segundo factor es la continua explotación de estas minas a lo largo del tiempo; esas labores destruirían, alterarían y ocultarían las huellas del periodo ibérico, aunque es muy sintomático que no se hayan descubierto restos de hábitats asociados. Y, por último, es posible que gran parte de las minas de esta cuenca no se explotaran y, por tanto, no se ocupara esta zona, algo marginal y alejada del principal oppidum del Alto Guadalquivir, Castulo ${ }^{15}$. Esto no quiere decir que otras áreas mineras, como la de Linares, Vilches o Arquillos, más cercanas a la

15 Esta zona, conocida en la antigüedad como saltus Castulonensis, fue famosa por el clima de inseguridad que se vivió en la misma, fundamentalmente, durante la II Guerra Civil, a mediados del s. I a. C. Prueba de ello es la carta que Asinio Polion, legado de Julio César en la Ulterior desde el año 44 a. C., escribió a su amigo Cicerón y en la que hace referencia tanto a los constantes latrocinios que se producían en esta zona como a la existencia de diferentes puestos establecidos por ambos bandos que examinaban o detenían a los mensajeros (tropas de Pompeyo y de César) (Cicerón: Ad fam. 10, 31, 1., según Contreras de la Paz, 1960).

mencionada ciudad, no se explotaran en estos momentos, como así ocurre, efectivamente, con la Mina del Polígono (Baños de la Encina, Jaén).

En este sentido, debemos recordar que nos encontramos ante una sociedad eminentemente campesina, dedicada a la agricultura y la ganadería. Estas comunidades ocuparían y explotarían fundamentalmente las tierras más fértiles y mejor comunicadas del Alto Guadalquivir y sus principales afluentes. Ello explicaría en gran medida que esta zona minera, poco fértil, aislada y alejada de los grandes centros urbanos, no fuera ocupada y sus minas no se explotaran hasta los momentos finales de época ibérica. La llegada de Roma coincide con una ocupación antrópica intensiva de esta cuenca minera, relacionada fundamentalmente con la explotación de los minerales de cobre y plomo/plata: fundiciones, fortines, poblados minero-metalúrgicos fortificados (Arboledas, 2010).

La segunda cuestión que nos puede ayudar a entender el origen y desarrollo de este asentamiento se refiere a la elección de su ubicación, junto al arroyo de los Valdeloshuertos, la principal vía natural de entrada al interior de la sierra de esta región. Asimismo, en esta falda S-SE del cerro 
confluyen diferentes veredas, cañadas y caminos reales de época medieval y moderna que conectaban y comunicaban la Meseta con el valle del Guadalquivir. Algunos de éstos pudieron conservar el trazado de vías de épocas precedentes (Jaramillo, 2005; Corchado y Soriano, 1963, 1969). Una de ellas podría ser la vía romana Castulo-Sisapo, cuyo recorrido pasaría por este valle de Valdeloshuertos para, posteriormente, adentrarse en la sierra hasta alcanzar Sisapo (Fig. 1) (Arboledas, 2010: 123-132).

En cuanto a la cronología de esta fase, el material arqueológico recuperado, fundamentalmente cerámico, nos proporciona un abanico temporal amplio que se extiende desde el s. V al II a. C. No obstante, la inexistencia de formas y producciones habituales en los contextos de la fase final de este periodo, como son los cuencos-lucerna o las producciones tardorrepublicanas de importación extrapeninsulares - paredes finas, barnices negros, ánforas itálicas o, incluso, de procedencia feniciopúnica-, nos lleva a pensar que el grueso del material cerámico recuperado -cerámica común, de cocina (ollas) o pintada (Figs. 10-12)-, que se puede datar tanto en la fase final como en la fase plena, pertenece a esta última (Pereira Sieso, 1988, 1989). Las cerámicas datadas entre el Ibérico antiguo y pleno, así como el ánfora de inspiración fenicia, aunque escasas (Fig. 7, n. $^{\circ}$ 1), estarían en la línea de una posible continuación del poblamiento existente desde el Bronce Final y refuerzan la cronología propuesta. Por tanto parece que la principal fase de ocupación ibérica de este cerro se encuadraría en un Ibérico pleno y continuaría hasta el s. II a. C. Serán las futuras intervenciones arqueológicas las que permitan corroborar o matizar la cronología propuesta.

El descenso ocupacional, e incluso el desalojo de este núcleo habitacional que podría estar evidenciando la drástica disminución de elementos de cultura material fechados en el periodo Ibérico final -de la que prácticamente sólo podemos destacar el kalathos ampuritano ${ }^{16}$ (Fig. 6)-, quizás

${ }^{16}$ La presencia del kalathos ampuritano sería una excepción; esta producción indígena, que técnicamente y desde el punto de vista decorativo es similar a las del $\mathrm{s}$ de Hispania, debe analizarse desde unos planteamientos distintos a las producciones extrapeninsulares. podría relacionarse con la llegada de los romanos a la zona a finales del s. III a. C., tras su victoria en la batalla de Baecula. Este hecho debió conllevar importantes transformaciones administrativas y económicas en la región derivadas de la nueva situación política y, por tanto, en las relaciones entre las aristocracias indígenas y los romanos. Entre estos cambios pudo estar una nueva estrategia de ocupación y explotación del territorio que provocaría la reducción e, incluso, el abandono de este asentamiento, en un momento en que se inicia la explotación intensiva de las minas de Sierra Morena. La inexistencia de materiales de importación -tan abundantes en cualquier contexto de esta etapa-, datados en época republicana y procedentes de regiones extrapeninsulares, también evidencia un posible abandono del asentamiento durante el Ibérico final, probablemente, a lo largo del s. II a. C.

A tenor de los datos aportados, interpretamos este yacimiento como un pequeño asentamiento en altura, con una situación estratégica privilegiada, que estaría relacionado con la explotación, defensa y control del territorio circundante. Aunque por el momento no podamos afirmar con rotundidad que se corresponda con un emplazamiento fortificado -tipo fortín/torre-, como los documentados en el Campo del Turia o la provincia de Jaén (Bonet, 1995; Ruiz y Molinos, 1984), sí parece compartir con éstos similares características: presenta pequeñas dimensiones, se ubica en la cima de un alto cerro y controla importantes zonas de paso desde una posición privilegiada. El único elemento no bien atestiguado hasta el momento, debido al precario nivel de conservación de los restos, es la existencia de estructuras defensivas que demuestren que nos encontramos ante un emplazamiento fortificado. Pero, a su vez, también presenta algunas particularidades de gran interés para futuras investigaciones, como es la existencia de restos del proceso metalúrgico que evidencian claramente su vinculación con la actividad minero-metalúrgica. Actualmente son las primeras evidencias metalúrgicas de este periodo documentadas en Sierra Morena oriental.

Centrándonos en cuestiones de tipo territorial, resulta necesario preguntarse con qué oppidum del entorno se relacionaría administrativamente este asentamiento. Como hemos indicado en líneas 
anteriores, por cercanía debería guardar relación con Castulo. No obstante, queremos apuntar un dato revelador y llamativo, y es que el cercano y pequeño oppidum de Cantigi ${ }^{17}$, dependiente bien de Castulo o bien de Iliturgi, no se funda hasta el Ibérico final, momento en el que el Cerro del Cueto parece ser abandonado. Es decir, tanto la fundación de este oppidum como el descenso ocupacional o abandono de este yacimiento son hechos coetáneos que podrían relacionarse con la nueva estrategia de organización, control y explotación del territorio impuesta por Roma tras la conquista de esta área. Ese cambio de estrategia poblacional, fechado a finales del s. III e inicios del II a. C., se ha constatado bastante bien en áreas cercanas del mismo Alto Guadalquivir, como, por ejemplo, el Giribaile, donde también se localizan importantes minas de cobre y plomo/plata (Gutiérrez Soler, 2002).

Por tanto, si damos por válida esta interpretación y seguimos el patrón teórico propuesto por Ruiz y Molinos del modelo político del pagus en el Alto Guadalquivir ${ }^{18}$, este yacimiento, asociado tanto a la explotación como a la defensa del territorio, pudo marcar probablemente el límite político por el NO del oppidum castulonense en las primeras estribaciones de Sierra Morena, ya que en el interior de la sierra no se ha constatado poblamiento alguno de ese periodo. Ello explicaría la situación del mismo, pero, a su vez, supondría aceptar que el territorio de este oppidum abarcaría no sólo la cuenca del río Guadalimar y sus afluentes, como se ha propuesto hasta el momento (Ruiz y Molinos, 2001, 2007), sino

${ }^{17}$ El inicio de la fase ibero-romana del pequeño oppidum de Plaza de Armas de Sevilleja (Espeluy) se sitúa en el s. II a. C., coincidiendo con la refundación de Isturgi por Sempronio Graco y una nueva valoración estratégicoterritorial del territorio (Ruiz et al., 1987: 252).

18 Según este, la construcción de un terreno estaba basada en 4 elementos: un oppidum primario, dinamizador del programa, cuya condición sería que en él la aristocracia hubiera conseguido un grado significado de consolidación (Castulo); una cuenca fluvial bien definida, en la que no hubiera conflicto con otras unidades de asentamiento, es decir, despoblada; un santuario dispuesto en el límite del nuevo territorio ocupado, como fórmula vecinal de colonización; y, por último, un oppidum más pequeño dependiente del principal (Ruiz y Molinos, 2001: 14; 2007). también la cuenca del río Guadiel -depresión de Linares-Bailén - hasta el frente montañoso de Sierra Morena, en un momento -ss. V-IV a. C.- en el que Castulo se había consolidado como uno de los grandes centros urbanos del Alto Guadalquivir, gracias al control que ejerció sobre las minas de su entorno más inmediato (Ruiz y Molinos, 2001, 2007).

\subsection{Fase romana}

El registro arqueológico demuestra que el cerro, tras un periodo de casi dos siglos en que sólo fue frecuentado de manera puntual/temporal, será nuevamente ocupado en época altoimperial. Como en la fase anterior, las evidencias arqueológicas documentadas de época romana se concentran en la parte más alta del cerro sin que, hasta el momento, se hayan hallado indicios en otras zonas de que se extendiese por las laderas del Cerro del Cueto (Castillo et al., 1990) ${ }^{19}$.

A tenor de los restos documentados, proponemos que dicha ocupación estaría vinculada a la construcción de un edificio aislado con cierto carácter monumental y, posiblemente, también porticado, de orden corintio. Por su anchura, el edificio cultual del Cerro del Cueto dispondría, como máximo, de dos columnas en la fachada principal, por lo que se trataría de un templete dístilo. Asimismo, este edificio tendría unas medidas que, a pesar de no haberse documentado su planta de manera completa, se asemejan bastante a multitud de pequeños edificios religiosos del tipo sacellum o aedicula, como podrían ser los casos hispanos del sacellum del Círculo Católico de Huesca -de 7,8 x 5,20 m (Asensio, 2003)-, del sacellum de la cavea del Teatro de Bílbilis, -con 11,5 x 7,5 m (Martín-Bueno y Sáenz, 2004)-, pero sobre todo del de Iuppiter Stator en el Cabezo Gallufo, bahía de Cartagena -de 10,45 x 5,79 $\mathrm{m}-$, dedicado por un liberto perteneciente a una de las principales familias productoras de plomo de esta región, los Aquinii (Amante et al., 1995; Antolinos y Noguera, 2013), y con el que también coincide en orientación -NE-SO-. Este último ejemplo es especialmente interesante no sólo

19 También Moya: op. cit. n. 12. 
por el edificio en sí, sino también por el contexto socioeconómico en el que se ubica. Se trata, como en nuestro caso, de una zona minera, el entorno suburbano de Carthago Nova y el área de Mazarrón, en cuyo contexto geográfico se han identificado restos arqueológicos, escultóricos y epigráficos que muestran la presencia de lugares de culto y edificios religiosos similares al del Cerro del Cueto, que constituyen manifestaciones materiales de los sacra privata, destinados a obtener la protección y beneficio de las divinidades tutelares de lugares específicos en el marco de las actividades económicas de los dedicantes, en este caso, las relacionadas con la minería y la metalurgia (Antolinos et al., 2010: 209-216).

Somos conscientes de que nuestra propuesta tiene debilidades, debido principalmente al estado de conservación del edificio, pero consideramos que los indicios acumulados bastan para proponer la posibilidad de su origen como sacellum/aedicula o bien monumento conmemorativo. Por ello, a continuación analizamos más detenidamente las dos propuestas interpretativas. De decantarnos finalmente por un pequeño edificio de culto observable desde casi cualquier punto o asentamiento de la depresión de Linares-Bailén, este estaría consagrado a una divinidad terrenal o natural, oficial o indígena, que no es posible identificar de momento. En este caso se podría tratar de un altar rural de carácter privado, dedicado por iniciativa particular, del mismo modo que los identificados en la Meseta septentrional (Hernández Guerra, 2000: 62-63). Además si aceptamos la vinculación de la inscripción analizada con esta construcción, podríamos suponer que formaría parte de un ara votiva, dedicada a la deidad origen del templete, quizás, por el particular por cuya iniciativa se erige esta capilla en lugar tan preeminente como el Cerro del Cueto ${ }^{20}$. El motivo para dicha fundación se nos escapa. Las ofrendas suponen una de las formas de piedad religiosa y de dependencia realizada a una divinidad; una

\footnotetext{
${ }^{20}$ La ubicación de este tipo de templetes rurales en lugares elevados es ciertamente habitual, lo cual se une en ocasiones a su carácter aislado (como sería nuestro caso) propio de las necesidades de intimidad y solemnidad para un uso tan específico como es el culto (Revilla Calvo, 2002: 193, 209).
}

vez conseguida, la fórmula de manifestar su agradecimiento sería mediante la realización de un templum [...] que confirma no sólo que el voto se ha conseguido, sino también que la unión con sus dioses era necesaria (Hernández Guerra, 2000: 65). Por otro lado, el carácter de la inscripción, tosco y en material local, es un fenómeno propio de la religiosidad popular y relacionado con un santuario "campestre". Efectivamente, esas aras podían estar al lado de templos o santuarios (Hernández Guerra, 2004: 155), como el caso que nos ocupa. El estado de la inscripción no permite reconocer la divinidad o divinidades que recibieron culto en esta capilla. Este hecho, junto a la deficiente conservación del templete mismo, imposibilita la obtención de mayor información.

Si finalmente aceptamos la interpretación de "CO..." en el epígrafe como referencia a un collegium, que podría ser religioso, se justificaría su presencia en este edificio. De hecho, como apunta Díaz Arińo (2004: 447) parafraseando a J. P. Waltzing, no puede concebirse un collegium romano sin estar vinculado al culto de una divinidad concreta, por lo que resulta pertinente la mención de una de estas asociaciones en el contexto de un edificio religioso.

Tampoco es descartable, si bien parece improbable, el hecho de que estemos ante una constitutor femenina, Felicia, por cuya iniciativa se fundaría un collegium, para lo que hay varios paralelos reconocidos (Saavedra Guerrero, 1992). Sin embargo, en este caso nos encontramos con un inconveniente: cuando se han documentado mujeres como constitutores collegiorum siempre se han circunscrito a asociaciones funerarias y ello obligaría a concluir que este edificio hubiera sido un mausoleo, opción que descartamos ante la ausencia de restos humanos en su interior o bien un monumento conmemorativo de carácter funerario. Su vinculación a un monumento conmemorativo, de cualquier carácter, también se encajaría con las características antes descritas para este edificio.

Pero volviendo de nuevo a la posible identificación del edificio con un pequeño templete o sacellum, podríamos plantear otras posibilidades, como la dedicación de un epígrafe por parte de un collegium religioso a la mecenas de su templo o a la benefactora del mismo, Felicia. Este argumento serviría, asimismo, para el caso de un edificio 
funerario; de ser así, la inscripción respondería a la dedicación otorgada por el collegium funerario a su benefactora, que tendría en el edificio que nos ocupa su lugar de enterramiento, en reconocimiento a una probable donación, en dinero o mediante algún elemento -estatua, ara, etc.- para enriquecer esta misma construcción (Saavedra Guerrero, 1992).

Las evidencias arqueológicas recuperadas, la cerámica y el capitel corintio sugieren que este edificio monumental se levantaría a partir de época altoimperial, posiblemente, a mediados del s. I d. C. Su existencia pudo prolongarse hasta época tardorromana, a tenor de la frecuentación del lugar que evidencian tanto la aparición de producciones cerámicas de dicha época (ss. IV-V d. C.), por ejemplo, la TSHTM o la TSFT, como la aparición de otro capitel corintio, datado en torno al s. IV d. C. En este caso, su existencia nos podría llevar a pensar, incluso, en la continuación del uso del edificio cultual/conmemorativo hasta estas fechas, el cual sufriría alguna reforma o reconstrucción en dicha etapa que justificaría su hallazgo en el lugar. Somos conscientes de que esta amplia secuencia de ocupación temporal está poco fundamentada, por lo que sólo pretende ser una propuesta de explicación a la aparición en este lugar de ambas manifestaciones arqueológicas, que ciertamente constituyen muy pobres evidencias para soportar cualquier tipo de hipótesis consistente.

Por tanto, atendiendo a las características y ubicación que presenta este edificio, habría que enmarcarlo y relacionarlo directamente con la estructura poblacional del territorio, actuando como un hito del paisaje, un marcador de pertenencia, en este caso religioso y sagrado, bien de una comunidad o de una parte de ella, en el límite natural entre el valle fértil y el interior de la sierra minera, visible desde numerosos puntos del territorio circundante. En los momentos en que parece fecharse este edificio, a mediados del s. I d. C.-s. II d. C., se asiste a una intensa ocupación de la depresión de Linares-Bailén con la aparición de numerosas villae y asentamientos rurales de diferentes dimensiones y tipología. Estos yacimientos son fundaciones ex novo y están orientados a la explotación agropecuaria de estas tierras que, hasta esa fecha, apenas habían sido explotadas o, al menos, no se ha constatado poblamiento anterior. La proliferación de dichos asentamientos apunta al nacimiento de una nueva economía, basada en la agricultura, en la decadente zona minera de Sierra Morena oriental, enmarcada dentro de la política de municipalización de época flavia, que supuso para las ciudades encontrarse con un territorio que hasta entonces había sido ager publicus (Arboledas, 2010: 110-115).

Concretamente, en el término municipal de Baños de la Encina, se han documentado 22 yacimientos arqueológicos de este tipo, asentamientos rurales de distinto carácter, desde los que, en la mayoría de los casos, existe un contacto visual directo con este edificio. Casi la totalidad se han adscrito a época alto- y bajoimperial sobre la base de los materiales recuperados durante las prospecciones arqueológicas y en las excavaciones realizadas en la villa de la Ermita de la Virgen de la Encina (Lizcano et al., 1990; Choclán y Pérez, 1990; Pérez et al., 1992) ${ }^{21}$ (Fig. 1). Es decir, gran parte de los mismos se fundarían en época altoimperial y su ocupación se prolongaría hasta bien entrado el s. V. En definitiva, parece evidente el carácter rural de este edificio cultual o conmemorativo y su vinculación con el territorio minero circundante, al igual que ocurre en otras áreas mineras peninsulares, como el entorno de Cartagena (Antolinos et al., 2010; Antolinos y Noguera, 2013), marcando un hito en el paisaje, justo en el límite con la sierra, que se divisaría desde toda la llanura circundante.

\section{Bibliografía}

Amante, M.; Martín Camino, M.; Pérez Bonet, M. a A.; GonzÁlez Fernández, R. y Martínez VILlA, M. a A. (1995): "El sacellum dedicado a Iuppiter Stator en Cartagena”, Antigüedad y Cristianismo, 12, pp. 533-562.

Antolinos, J. A. y Noguera, J. M. (2013): "Los recursos minerales del ager de Carthago Nova: explotación, modelos de gestión territorial y jerarquización de los asentamientos". En Fiches, J. L.; Plana-Mallart, R. y Revilla, V. (eds.): Paisajes rurales y territorios en las ciudades del Occidente romano. Gallia e Hispania. Barcelona, pp. 341-351.

${ }^{21}$ Cf. también Casado: op. cit. n. 3. 
Antolinos, J. A.; Noguera, J. M. y Soler, B. (2010): "Poblamiento y explotación minero-metalúrgica en el distrito minero de Carthago Nova". En Noguera, J. M. (ed.): Poblamiento rural romano en el Sureste de Hispania. 15 años después. Actas II Jornadas de poblamiento rural romano en el sureste de Hispania (Murcia, 2009). Murcia, pp. 167-231.

ARboledas, L. (2010): Minería y metalurgia romana en el Sur de la Peninsula Ibérica: Sierra Morena oriental. BAR Int. Ser., 2121. Oxford: Archaeopress.

Arboledas, L. y Contreras, F. (2010): "La mina del Polígono o Contraminas (Baños de la Encina, Jaén). Evidencias de la explotación de mineral de cobre en la antigüedad", Cuadernos de Prehistoria y Arqueologia de la Universidad de Granada, 20, pp. 355-379.

Asensio, J. A. (2003): "El sacellum in antis del 'Círculo Católico' de Huesca (Osca, Hispania Citerior), un ejemplo precoz de arquitectura templaria romana en el valle del Ebro", Salduie, 3, pp. 93-127.

Bonet, H. (1995): El Tossal de Sant Miquel de Llíria. La antigua Edeta y su territorio. Valencia: Diput. de Valencia.

Cantarero, J. M. (coord.) (2004): De veredas y caminos por la comarca minera de Sierra Morena. De veredas y caminos por la Andalucía rural n. 1. Sevilla: C. de Turismo y Deporte de la J. de Andalucía.

Castillo, J. L.; Lara, J. C. y Choclán, C. (1990): "Excavación arqueológica de urgencia en el entorno del castillo de Baños de la Encina (Jaén)", Anuario Arqueológico de Andalucía 1988, III. Actividades de Urgencia, pp. 191-196.

Choclán, C. y Pérez Bareas, C. (1990): "Prospección con sondeos estratigráficos en la ermita de La Virgen de La Encina (Baños de La Encina, Jaén)", Anuario Arqueológico de Andalucía 1988, III. Actividades de Urgencia, pp. 148-156.

Conde i Berdòs, M.a J. (1991): "Les produccions de kálathoi d'Empüries i la seva difusió mediterrània (segles II-I a. C.)", Cypsela, 9, pp. 141-168.

Contreras, F. (coord.) (2000): Proyecto Peñalosa. "Análisis histórico de las comunidades de la Edad del Bronce del Piedemonte Meridional de Sierra Morena y Depresión Linares-Bailen”. Arqueología Monográficas, 10. Sevilla.

Contreras, F. y DueÑAs, J. (dirs.) (2010): La minería y la metalurgia en el Alto Guadalquivir: desde sus origenes hasta nuestros días. Jaén: Instituto de Estudios Giennenses de Jaén.

Contreras, R. (1960): "Bandolerismo hispano y guerra civil en el Salto Castulonense en el año 40 anterior a la Era Cristiana (de una carta de Asinio Polión a Cicerón)”, Oretania, 4, pp. 149-154.
Corchado, M. (1963): "Pasos naturales y antiguos caminos entre Jaén y la Mancha", Boletín del Instituto de Estudios Giennenses, 38, pp. 9-37.

Corchado, M. (1969): "Estudio sobre vías romanas entre el Tajo y el Guadalquivir", Archivo Español de Arqueología, 42, pp. 29-158.

DíAz ArIÑo, B. (2004): "Heisce Magistreis. Aproximación a los collegia de la Hispania republicana a través de sus paralelos italianos y delios", Gerión, 22, pp. 447-478.

Domingo Magaña, J. (2011): Capiteles tardorromanos y visigodos en la Península Ibérica (siglos IV-VIII d.C.). Tarragona: ICAC.

GonZÁlez RomÁn, C. y MANGAS, J. (1991): Corpus de Inscripciones Latinas de Andalucía. Volumen III. Jaén. Sevilla: Dirección General de Bienes Culturales.

Gutiérrez Behemerid, M. a A. (1983): "El capitel corintizante: su difusión en la península ibérica", Boletin del Seminario de Arte y Arqueología, 49, pp. 73-104.

Gutiérrez Behemerid, M.a A. (1992): Capiteles romanos de la Península Ibérica. Valladolid: Univ. de Valladolid.

Gutiérrez Soler, L. M. (2002): El oppidum de Giribaile. Jaén: Univ. de Jaén.

ETXEBARRÍA, A. (2008): Los foros romanos republicanos en la Italia centro-meridional tirrena. Origen y evolución formal. Madrid: CSIC.

HernándeZ Guerra, L. (2000): "Ejemplos de dependencia divina en la Meseta Septentrional", Arys, 3, pp. 59-66.

Hernández Guerra, L. (2004): "Pequeños altares en el área de la Meseta septentrional", Hispania Antiqua, 28, pp. 154-168.

JARAMILLO, A. (2005): Recursos y materias primas en la Edad del Bronce del Alto Guadalquivir, medioambiente y el registro arqueológico en la cuenca del río Rumblar. Granada: Univ. de Granada.

Lizcano, R.; Nocete, F.; Pérez Bareas, F.; ConTRERAS, F. y SÁnchez RuIZ, M. (1990): "Prospección arqueológica sistemática en la cuenca alta del río Rumblar", Anuario Arqueológico de Andalucía 1987. II. Actividades Sistemáticas, pp. 51-59.

Martín-Bueno, M. y SÁenz Preciado, J. C. (2004): "Los programas arquitectónicos de época JulioClaudia de Bilbilis". En Ramallo, S. (ed.): La decoración arquitectónica en las ciudades romanas de Occidente. Cartagena, pp. 257-273.

MATA, C. y Bonet, H. (1992): "La cerámica ibérica: ensayo de tipología", Trabajos Varios del Servicio de Investigación Prehistórica, 89, pp. 117-173.

Molinos, M. (1992): Excavaciones en la Plaza de Armas de Puente Tablas. Jaén. 
Nocete, F.; SÁnchez Ruiz, M.; Lizcano, R. y ConTRERAS, F. (1987): "Prospección arqueológica sistemática en la cuenca baja/media-alta del río Rumblar", Anuario Arqueológico de Andalucía 1986. II. Actividades Sistemáticas, pp. 75-78.

Pereira, J. (1988): "La cerámica ibérica de la cuenca del Guadalquivir. I. Propuesta de clasificación", Trabajos de Prehistoria, 45, pp. 143-173. http://dx.doi.org/10.3989/tp.1988.v45.i0.608

Pereira, J. (1989): "La cerámica ibérica de la cuenca del Guadalquivir. I. Cronología”, Trabajos de Prehistoria, 46, pp. 149-159. http://dx.doi.org/10.3989/tp.1989.v46.i0.592

Pérez Bareas, C.; Lizcano, R.; Moya, S.; Casado, P.; Gómez del Toro, E.; Cámara, J. A. y MartíNEZ OCAÑA, J. L. (1992): "II campaña de prospecciones arqueológicas sistemáticas en la depresión Linares-Bailén. Zonas meridional y oriental, 1990", Anuario Arqueológico de Andalucía 1990. II. Actividades Sistemáticas, pp. 86-95.

RAMALLO, S. (ed.) (2004): La decoración arquitectónica en las ciudades romanas de Occidente. Murcia: Univ. de Murcia.

Revilla, V. (2002): "Santuarios, élites y comunidades cívicas: Consideraciones sobre la religión rural en el Conventus Tarraconensis". En MARCO, F.; PINA, F. y Remesal, J. (eds.): Religión y Propaganda politica en el mundo romano. Barcelona: Univ. de Barcelona, pp. 189-226.

Ruiz Rodríguez, A. y Molinos, M. (1984): “Elementos para un estudio del patrón de asentamiento en las campińas del Alto Guadalquivir durante el horizonte pleno ibérico (un caso de sociedad agrícola con Estado)", Arqueología Espacial, 4, pp. 187-206.

Ruiz Rodríguez, A. y Molinos, M. (2007): Iberos en Jaén. Jaén: Univ. de Jaén.

Ruiz Rodríguez, A.; Molinos, M.; Gutiérrez Soler, L. M. y Bellón, J. P. (2001): "El modelo político del pago en el Alto Guadalquivir (s. IV-III a.n.e.)". En Territori politic i territori rural durant l'edat del Ferro a la Mediterránea Occidental (Actes de la Taula Rodona celebrada a Ullastret). Monografies d'Ullastret, 2. Gerona, pp. 11-22.

Ruiz Rodríguez, A.; Molinos, M.; Hornos, F. y CHOClÁN, C. (1987): "El poblamiento ibérico en el Alto Guadalquivir". En RuIZ, A. y Molinos, M. (eds.): Iberos. Actas I Jornadas sobre el Mundo Ibérico. Jaén: Ayto. de Jaén, pp. 239-256.

Ruiz Rodríguez, A.; Molinos, M.; López Rozas, J.; Crespo, J.; Choclán, C. y Hornos, F. (1983): "El horizonte ibérico antiguo del Cerro de la Coronilla (Cazalilla, Jaén). Cortes A y F”, Cuadernos de Prehistoria de la Universidad de Granada, 8, pp. 251-299.

SAAVEDRA, M. ${ }^{a}$ D. (1991): "Manifestaciones del poder femenino en la vida colegial", Studia Histórica. Historia Antigua, 9, pp. 109-114.

SaAVedra, M. ${ }^{a}$ D. (1992): "Constitutores Collegiorum: el papel de las mujeres en la fundación de collegia en Roma”, Polis, 4, pp. 209-214. 